\title{
00
}

\section{Evolución de la gestión tutelar del patrimonio cultural: un hilo de 25 años trazado desde la revista $\mathrm{PH}$}

\author{
Eduardo Mosquera Adell \\ Dpto de Historia, Teoría y Composición \\ Arquitectónicas, Universidad de Sevilla
}

Al cumplirse hace unos meses su primer cuarto de siglo, encontramos una significativa ocasión para remarcar algunos de los pasos a través de los que el acompañamiento de la revista $\mathrm{PH}$ al quehacer patrimonial ilustra la evolución de su tutela, desde la órbita de su gestión. Lo haremos con especial atención respecto a quienes tienen una responsabilidad en dicha labor ante la ciudadanía, escenario en el que el Instituto Andaluz del Patrimonio Histórico ocupa una posición especialmente reconocible, cuando menos en el ámbito de Andalucía.

El testimonio de ese recorrido, que no es un simple hilo en el puro sentido lineal, sino más bien el resultado de un complejo trenzado, con flecos que recoger aún, ha quedado en buena medida registrado en las páginas de la revista $\mathrm{PH}$ desde diciembre de 1992, a través de la propia evolución que su rítmica publicación ha manifestado en sus diversas etapas.

Unos tiempos de la revista con diferentes nombres, como Boletín Informativo (del 1 al 13, en sus tres primeros años), $\mathrm{PH}$. Boletín del Instituto Andaluz del Patrimonio Histórico (del 14 al 40/41, a partir de marzo de 1996 y hasta diciembre de 2002), $\mathrm{PH}$ a secas en su portada (del 42 al 58, de febrero de 2003 a mayo de 2006), retomando el nombre largo en el 59 y asumiendo el actual de revista $\mathrm{PH}$ en febrero de 2009. En esta trayectoria, que el propio IAPH identifica en seis etapas (una de ellas desdoblada), se han tenido distintos ISSN, diferentes aspectos, desde el modesto formato de edición y papel de sus primeros cinco números, hasta la llegada del cuché en el 6 y del color en el 13; desde el recurso al blanco y negro en portada y a los colores planos en la maquetación (del 42 al 58, durante más de un trienio) o el empleo del color en toda la publicación, incluida la portada, a partir del 59 (julio de 2006), que abrió con un significativo editorial'; y el paso a una versión exclusivamente digital en octubre de 2013, con el número 84 , hasta alcanzar al 94 recientemente, en junio de 2018.

Unos tiempos en los que la organización de las secciones se ha ido complejizando y la aparición de tematizaciones y números monográficos nos ha permitido acceder a no pocos episodios de interés, con unos plazos largos de elaboración y de pausada recepción. Mientras que otros trabajos se fraguaron bajo un notable sentido de la oportunidad, que con absoluta fluidez oscila de lo planificado a lo instintivo, confiriéndole este amplio espectro su inconfundible personalidad en su ya larga historia. $Y$ hay que destacar ese interés y relevancia por cuanto la pertinencia de muchas aportaciones se ha acompasado con el decurso de la evolución de la gestión tutelar del patrimonio cultural. Un periodo vivido, ya largo, en que parcialmente la acompañó en su andadura la revista hermana $\mathrm{PH}$ investigación ${ }^{2}$ y, sobre todo, la continuidad editorial por parte del IAPH de 
"En 1993 la idea de difusión reclama la apertura a un proyecto de configuración de un referente. Un boletín que en su andadura temprana se centra en emitir noticias y en exponer opiniones. Que, poco a poco, en blanco y negro y cuché, se convierte en un reflejo de la interdisciplinariedad, de abordar y centrar temáticas por conceptos, problemáticas, territorios... que no tiene parangón en nuestro país"
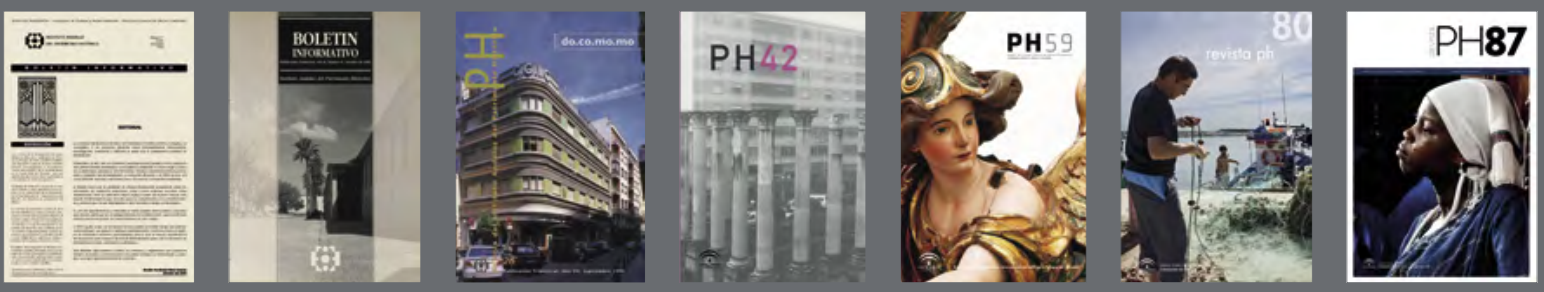

Portadas de revista $\mathrm{PH}$ en las distintas etapas de su trayectoria

sus Cuadernos, con distintas líneas, presentes asimismo desde 1992 y con los que la revista ha interactuado en no pocas ocasiones ${ }^{3}$.

Tengamos en cuenta que en los 25 años que ha visto la luz la revista $\mathrm{PH}$, desde el impulso que coordinó ejemplarmente Marcelo Martín, hasta la labor de equipo de María Cuéllar, Cinta Delgado y Carmen Guerrero y, diríamos que de todo el IAPH, nos encontramos con la cifra de aproximadamente 2.000 autoras y autores que han escrito en sus páginas. Forzosamente hay que acudir a una visión simplificada, pero que procurará ser demostrativa del alcance de lo publicado en este tiempo, en relación con una cuestión tan crucial como la evolución de la gestión de la tutela patrimonial, en la que es una guía imprescindible, trascendiendo del marco andaluz, como han insistido cualificadas voces.

\section{Primeros pasos}

hacia una experiencia

y unos saberes a difundir

La revista y el Instituto que le da carta de naturaleza son fieles a unos orígenes y a un recorrido en el que la presencia y activo papel tutelar sobre los bienes culturales y el despliegue del proyecto comunicativo se interrelacionan.

Andalucía se ha pensado a sí misma, desde su formulación como Comunidad Autónoma dotada de órganos de gestión política y administrativa propios de su dimensión, con la reivindicación de sus formas de cultura específicas que son un puente para su universalidad.

Significativamente, en un momento temprano, la construcción inicial de su tratamiento de la cultura (PÉREZ YRUELA; VIVES, 2012) conlleva la creación del Instituto de Cultura Andaluza (Decreto 135/1982, de 13 de octubre) y, para el marco en que nos situamos, el arranque se produce con un instrumento jurídico propio, la Ley 8/1983, de 3 de noviembre, de Bibliotecas, un acto de base, fundacional diríamos, que significativamente arranca con el patrimonio bibliográfico y parte del documental ${ }^{4}$. Es bien sabido que para la extensión de la acción desde Andalucía sobre su propio patrimonio hay que esperar al Real Decreto 864/1984, de 29 de febrero, sobre traspaso de funciones y servicios del Estado a la Comunidad Autónoma de Andalucía en materia de Cultura. Entre las funciones que se traspasan, se encuentran las referidas al ámbito del patrimonio, concretamente en materia de "Patrimonio histórico, artístico, monumental, arqueológico, paleontológico, etnológico, archivos, bibliotecas, museos y demás colecciones de naturaleza análoga, y servicios de Bellas Artes".

Este panorama tuvo un doble proceso: por una parte, la producción de legislación temprana de archivos, museos, bibliotecas, etc., para 
"La decidida apuesta

del Instituto Andaluz del

Patrimonio Histórico en sus

más de 25 años de trayectoria

por la investigación científica

y técnica de excelencia ha

conducido a su registro oficial

como agente del Sistema

Andaluz del Conocimiento,

en la clasificación concreta de

Instituto de Investigación"

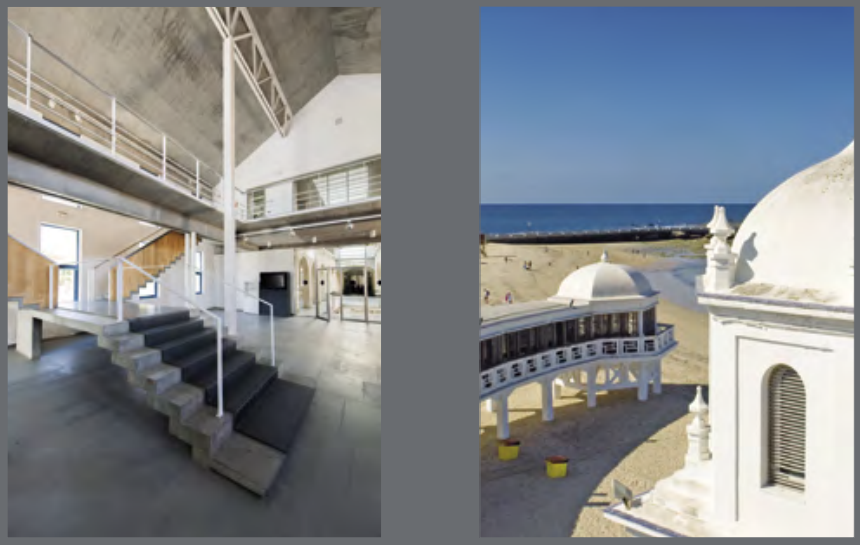

Sedes del Instituto Andaluz del Patrimonio Histórico en el monasterio

de la Cartuja de Sevilla y del Centro de Arqueología Subacuática en el

balneario de la Palma en Cádiz. Fotos Fondo Gráfico IAPH

resolver el conflicto entre titularidad estatal y gestión autonómica 5 . Por otra, el momento de las transferencias de las competencias exclusivas se vive con la llegada a Sevilla de documentación, no ya sin inventariar, sin clasificar, sino desconocida en gran parte de su entidad, relativa a aquellos bienes sobre los que descansaban medidas legales y administrativas sectoriales, si se nos permite en este punto tomar ya la terminología de bienes culturales que instauraría poco después la Ley 16/1985, de 25 de junio, del Patrimonio Histórico Español. Una situación que abriría la necesidad de organizar y articular un escenario en el que las carencias, indefiniciones o ausencias, y otras situaciones incluso sorprendentes, aquejaban a los bienes culturales andaluces. En apenas seis o siete años se vive un trepidante proceso que tiene paralelos con el de la Commissione d'indagine per la tutela e la valorizzazione del patrimonio storico, archeologico, artistico e del paesaggio, que realizó un renombrado trabajo en los años sesenta, presidido por Francesco Franceschini ${ }^{6}$, atendiendo al mandato de la ley italiana de 1964 para la revisión de las leyes del patrimonio cultural nacional, las estructuras y ordenamientos administrativos y la adecuación financiera (FRANCESCHINI, 1967). De hecho, es cuando toma carta de naturaleza una visión evolucionada de la tutela de los bienes culturales, donde Andalucía - dos décadas después- abandera en el contexto autonómico la aportación de criterios avanzados. Sí cabe recordar dentro de los años que preceden a la revista $\mathrm{PH}$ este tiempo de fundamentación de su proceder, que se corresponde con el mandato de Javier Torres Vela como consejero de Cultura (1984-1990) y Bartolomé Ruiz como director general (1983-1988), bajo distintas denominaciones hasta acuñarse la de Bienes Culturales. La apertura de las comisiones andaluzas de bienes culturales (patrimonio monumental, arqueología, etnología y museos y bellas artes) define un tono de expertización sumamente alto para la serie de avatares decisorios, con base sobre todo en la problemática de la protección que se acumula en ese tiempo, recogido por Ignacio Henares en un trabajo, acompañado de otros interesantes artículos, como los de José Castillo Ruiz, Celia Martínez Yáñez o Ángel Isac, que aclaran la coyuntura vivida (HENARES CUÉLLAR, 2010).

De hecho, el análisis de los bienes recibidos en la documentación ministerial, su tipología jurídica y su régimen de protección (estar declarados o con expedientes incoados para su declaración), abrió pronto la necesidad de efectuar el debido reconocimiento del patrimonio andaluz, de los bienes que lo integraban (individualmente o por la vía de colectividades asumidas de disposiciones previas, por la mencionada Ley 16/1985)7, produciéndose una dinámica pulsión para una puesta al día pública, desde el cuestionamiento de aquello que era representativo y, sobre todo, de las ausencias. En 1985 se activó el Plan de Actuación Especial en materia de Bellas Artes (PAEMBA), 

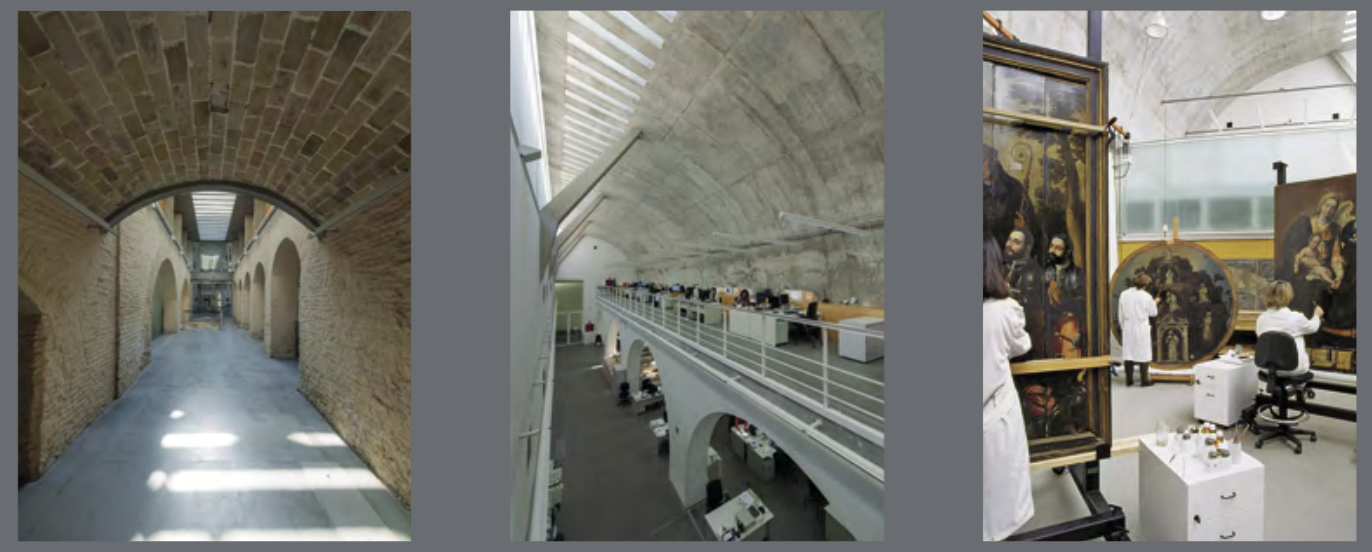

que efectuó un análisis individualizado del estado en que se encontraban los bienes culturales, y el correspondiente cruce de datos, empleando a numerosos técnicos, y que fue la base de los anexos para el documento de Avance del Primer Plan General de Bienes Culturales (PGBBCC), aprobado unánimemente en el Parlamento en 1989. De modo que apareció un tercer nivel de inmuebles de interés (no declarados, ni con expediente incoado) que quedaría anexado al Primer PGBBCC. La organización del mapa de los bienes culturales conllevaría el análisis de su estado de conservación y la apertura de una serie de programas y planes que iluminan una visión más sistemática. La planificación de acciones, con un precedente como el Plan Nacional de Catedrales, se acompañará de numerosos planes individualizados en el documento, entre los que figura la Alhambra, cuyos estatutos en relación con su gestión desde Andalucía se aprobaron en $1986^{\circ}$, y una nueva institución que se proyecta poner en marcha, el Instituto Andaluz del Patrimonio Histórico (IAPH) ${ }^{10}$.

\section{Otra idea de tutela}

patrimonial y de su gestión:

institucionalización

y planificación

La idea de una tutela lineal - de tradición italiana, basada en el conocimiento, la intervención y la puesta en valor- es ahora procesual, permanente, circular, relacional. Emerge en un escenario que reclama la progresiva potenciación de la dimensión territorial del patrimonio y la definición de una nueva gestión que otorgue una nueva caracterización a los bienes ${ }^{11}$. La inserción en la sociedad exige romper gradualmente la trayectoria erudita y tecnocrática de la protección y la conservación, afinándose con la puesta en valor, la difusión y la investigación. La planificación será a partir de ese momento el reflejo de una concreción de la práctica tutelar que tiene su espejo en la propia estructura orgánica de la gestión de los bienes en la Dirección General de Bienes Culturales, desde la concepción que Javier Torres Vela y Bartolomé Ruiz le otorgan administrativamente.

Pero será una Italia culturalmente efervescente desde los años sesenta, como ya hemos anticipado, la que asuma un papel de guía especialmente significativo para el caso del salto cualitativo de la tutela patrimonial en Andalucía. La teoría de los bienes culturales (ALIBRANDI; FERRI, 1978) y de su protección (ALIBRANDI; FERRI, 1988) alcanza una firme base jurídica, que en Andalucía se analiza también (BARRERO RODRÍGUEZ, 1990).

Un acercamiento significativo fue el seminario italoespañol Restauración arquitectónica hoy, que tuvo lugar en octubre de 1987 en la Academia Española en Roma y en San Michele, sede del Istituto Centrale per il Restauro (ICR) y el Ministero dei Beni Culturali, entre otros organismos, contando con 
significativos gestores y expertos patrimoniales de Madrid, Barcelona y Andalucía, según se recogió en la revista $\mathrm{PH}$ (FERNÁNDEZ-BACA CASARES, 2001). A finales de 1988 se produce en Roma el Convegno Memorabilia que, gracias a la anticipadora visión del entonces director general de Bienes Culturales José Guirao, concentra a miembros de las comisiones andaluzas de bienes culturales y a otros técnicos en sus sesiones. La experiencia se constituye en un referente directo para el Primer Plan General de Bienes Culturales de Andalucía y todos los debates que sobre los bienes y las instituciones se están produciendo. Los sucesivos trabajos previos de Memorabilia, coordinados por Franceso Perego (PEREGO, 1987), sedimentaron en el material de este congreso (CLEMENTI; PEREGO, 1988) ${ }^{12}$. Los principios sistematizados por Alberto Clementi (visión territorial, nueva cultura relacional, nueva ciencia, nueva economía en torno a los bienes culturales...), que él mismo recalcaría presencialmente en el curso La tutela de los Bienes Culturales. Fin de siglo, impartido en Baeza, se convierten en guía de la planificación que se está redactando y del marco de instituciones que se van a crear, con el IAPH definido programáticamente en el Plan, y que se establecerá como referente desde 1989, al crearse como servicio sin personalidad jurídica de máxima especialización en la tutela patrimonial13. Su creación coincide con una iniciativa editorial donde se rememoran diez años de gestión de la cultura desde Andalucía, con textos de diversos estudiosos especialmente activos en las comisiones patrimoniales, como Arturo Ruiz o Víctor Pérez Escolano, entre otros (CONSEJERÍA DE CULTURA, 1989).

No serán tanto los programas y planes que tienen en el Primer Plan una vigencia de 1989 a 1995, y su influjo en uno de los programas singulares, el Instituto Andaluz del Patrimonio Histórico, sino el trabajo - en gran medida de este-con proyectos lo que dé carta de naturaleza a la estructura allí definida, apoyada en la documentación, intervención, formación y difusión, investigación por consolidar, con una gestión administrativa y un modo de operar sobre los bienes culturales que se van haciendo día a día.

\section{La construcción de una identidad en medio de un nuevo marco}

Se definiría así el sustrato de un nuevo marco tutelar que superaría el escenario tradicional y transferido desde el Gobierno central, de los monumentos como figuras predominantes - entre los inmuebles-y las colecciones establecidas en el caso preferente de los bienes muebles. El Primer Plan General de Bienes Culturales comenzó a desarrollar la idea de inversión en los bienes, en términos cuantitativos y de localización territorial y conceptual, comenzando a tomar cuerpo la tecnificación y la complejización de la integralidad de la tutela, cuestiones que reclamaron la constitución de un órgano de máxima especialización. Estos conceptos derivados del debate italiano y recogidos en el Primer PGBBCC devendrán en su definición estructural en la que se plasma la idea de tutela que se quiere proyectar desde 1989 con un IAPH en marcha. La elección estratégica del locus para el IAPH, cargado de simbolismo, una antigua cartuja, luego factoría de loza finalmente abandonada que deviene en fábrica patrimonial de Andalucía, es otro factor a tener en cuenta. El IAPH se instala en 1990 en su sede, que es intervenida por el arquitecto Guillermo Vázquez Consuegra. Con anterioridad, el Plan Director de Usos de la Cartuja, coordinado por la arquitecta María Teresa Pérez Cano, había definido su sector dentro de los cuatro en que se dividió la Cartuja y estudiado la viabilidad de implantar un instituto con un programa coherente con las características previsibles en el futuro $\mathrm{IAPH}$, hecho que había requerido la visita a otros institutos como referentes, por parte de diversos expertos ${ }^{14}$

El simbolismo del IAPH llega más tarde a su segunda sede permanente, en el antiguo balneario de Nuestra Señora de la Palma y el Real, que alberga al Centro de Arqueología Subacuática en la gaditana Caleta, un espacio emblemático de la navegación marítima histórica ${ }^{15}$.

Entre 1989 y 1992 se producen acontecimientos relevantes que sumar a la creación y alojamiento del IAPH, como son la promulgación de una ley de patrimonio de Andalucía y la convivencia eventual con la Exposición Universal de 1992. Más tarde, sobre el recinto de la muestra, se producirá la configuración de un parque científico y tecnológico en el sector urbano de la Cartuja, que refuerza el discurso de localización del Instituto.

A estos factores, y en la idea de cómo se configura el IAPH, debe considerarse en el plano operativo que, gradualmente con un colectivo en general joven y la notable presencia de la mujer, se da paso a una práctica tutelar innovadora desde la más completa asunción de la interdisciplinariedad, a una apertura a nuevos patrimonios, al interés no ya solo por lo contextual, sino por un entendimiento de lo ambiental, la cultura de lo preventivo y las pautas de sostenibilidad propias de los modelos tendenciales de desarrollo ${ }^{16}$ auspiciados por aquellas políticas culturales donde el patrimonio es un componente ${ }^{17}$ esencial. 
En 1991 el IAPH arranca con el trabajo de la Capilla Real de Granada. Será una entrada en la que la internacionalización tiene su primer encaje, con el romano Istituto Centrale per il Restauro y el Institut royal du Patrimoine Artistique (KIK/ IRPA) de Bélgica. Se coincide en el tiempo con el cambio que representa en el ámbito de los bienes culturales la promulgación de la Ley 1/1991, de 3 de julio, de Patrimonio Histórico de Andalucía, primera de la Comunidad, en la que se abre la vía a la acentuación de los rasgos de lo local, de los factores de identidad, que se concentran en la definición de nuevas tipologías jurídicas como el lugar de interés etnológico y la actividad de interés etnológico, además de profundizar en el hecho de la protección. Se complementa con actualizaciones de las leyes tempranas: Ley 3/1999, de 28 de abril, de Modificación de la Ley 3/1984, de 9 de enero, de archivos y, más adelante, la comentada Ley 16/2003, de 22 de diciembre, del Sistema Andaluz de Bibliotecas y Centros de Documentación

Con el Primer PGBBCC en marcha, y el IAPH en desarrollo, la información sobre los bienes culturales se va organizando, y las experiencias de intervención del IAPH se van produciendo. La tutela se practica desde un principio de integralidad.

Tras los fastos de 1992 y las grandes inversiones en patrimonio (Cartuja recuperada en gran medida, inmuebles restaurados con la colaboración del Banco de España, edificios con conexión americanista), aparece un enfriamiento en materia de gasto y una gestión que reclama resultados. Desde el IAPH se programan a finales de 1992 un conjunto de cursos y debates que, desde la perspectiva de la formación y la comunicación, aparecen como el refuerzo ideológico de un nuevo proceder. Precisamente en 1992 la idea de difusión reclama la apertura a un proyecto de configuración de un referente. Un boletín que en su andadura temprana se centra en emitir noticias y en exponer opiniones. Que, poco a poco, en blanco y negro y cuché, se convierte en un reflejo de la interdisciplinariedad, de abordar y centrar temáticas por conceptos, problemáticas, territorios... que no tiene parangón en nuestro país. El entonces escueto Boletín Informativo IAPH ve la luz el 1 de diciembre de 1992 con un editorial de su director Román Fernández-Baca y con noticias del mundo del patrimonio, que irá combinando con opiniones en las sucesivas entregas.

Los trabajos con la Capilla Real abren el paso a una colección editorial del IAPH que arranca también en 1992, con un primer cuaderno, Un proyecto para la Capilla Real de Granada: Teorías, métodos y técnicas aplicadas a la conservación del patrimonio mueble, en una línea de publicaciones que, con los resultados de proyectos y los debates indicados, se multiplicará de forma coetánea a cómo irá tomando cuerpo la revista $\mathrm{PH}^{18}$

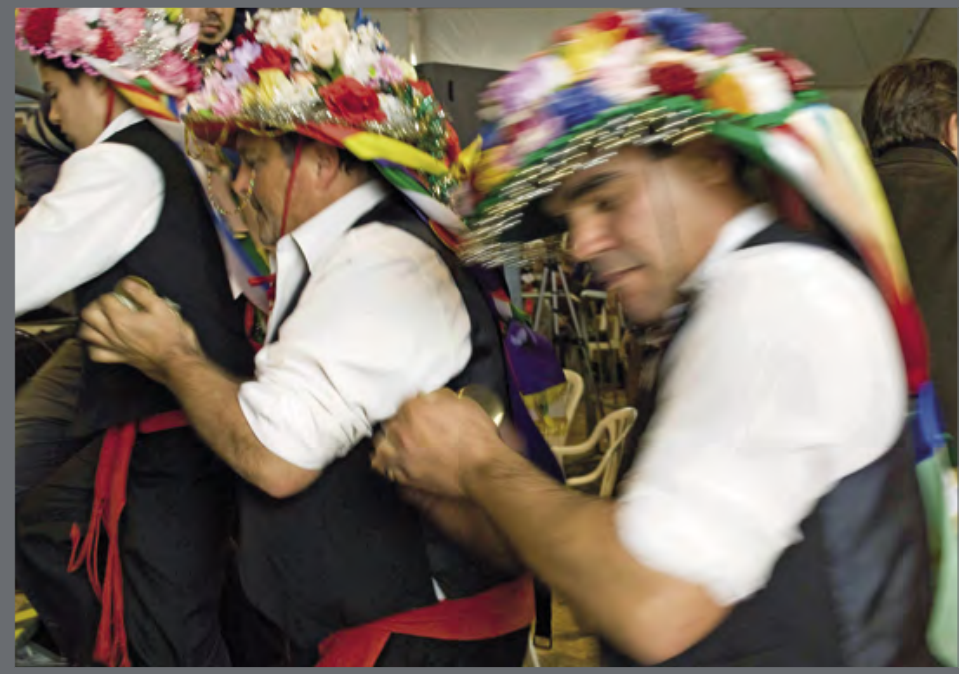

"El protagonismo de las personas conduce a retomar los temas etnológicos en revista $\mathrm{PH}$, abiertos a finales de los ochenta y en los trabajos de principios de los noventa" 


\section{La confirmación institucional y el giro a otra dinámica productiva. Continuidades y nuevos acentos desde la revista $\mathrm{PH}$}

Otra forma, otro modelo de gestión, se ha generado con la Capilla Real, mostrando la capacidad de convenio y el desarrollo de talleres y laboratorios, organizados en el IAPH - Raniero Baglioni, Rosario Villegas o María José González son algunas de las figuras pioneras - como un motor de continuidad del mismo, aunque en esta intervención, como en otras posteriores (Puerta de Córdoba en Carmona de 1995, Santa Cueva de Cádiz...), se cuente con arquitectos como Pedro Salmerón o Mercedes Linares y Antonio Tejedor, con vinculaciones diferentes al IAPH. En paralelo a estas intervenciones que reflejan un método y unos futuros protocolos, especialmente también para el caso de los bienes muebles, con una imagen de tecnificación, la revista $\mathrm{PH}$ abre otra vía con el tema del patrimonio y desarrollo.

En efecto, inaugura en sus primeros compases la aproximación a la asociación de patrimonio con desarrollo, de forma que alcance a la totalidad de la población de un territorio, más allá de una cuestión identitaria (a menudo discutida en la diatriba política, pero destacada en el concierto estatal). La concepción de los bienes culturales no en términos de gasto, sino de recursos sociales con sus plusvalores, marca una nueva impronta territorial. El acento por lo local, un encuadre pendiente desde las transferencias, y sujeto a continuas revisiones, conduce a estudiar políticas locales en términos de desarrollo donde el patrimonio ha de jugar sus bazas, en términos de políticas culturales. Es un tiempo en que el diseño de la Ruta Bética Romana o las rutas del Legado Andalusí persigue una nueva condición territorial de la percepción, uso y gestión del patrimonio, con desigual fortuna respecto a la atención que han despertado en otros focos. En esta línea, el inventario de recursos culturales de la comarca jiennense de La Loma (INVENTARIO, 1994) fue de por sí un recuento significativo de la nueva escora de la acción tutelar territorializada, que deriva más adelante en la exitosa inscripción de úbeda y Baeza en la Lista de Patrimonio Mundial sobre un primer modelo urbano (con ciudades medias) y a la vez territorial en Andalucía.

Desde su arranque, la revista del IAPH aborda un protagonismo claro en la cuestión del desarrollo, que trasladará luego a los documentos de planificación de la Consejería (ROMERO MORAGAS, 1993). El patrimonio, para Carlos Romero, es un "recurso para el desarrollo social y cultural, por su potencialidad educativa, científica, divulgativa y de creación cultural, que contribuye a consolidar la identidad local". Esta línea de trabajo adquiere otra dimensión con el documento titulado Bases para una Carta sobre Patrimonio y Desarrollo en Andalucía (FERNÁNDEZ SALINAS,
"EI IAPH desarrolla un amplio espectro de intervenciones en el recorrido en continuidad, del que la revista PH expone procesos y aporta resultados"
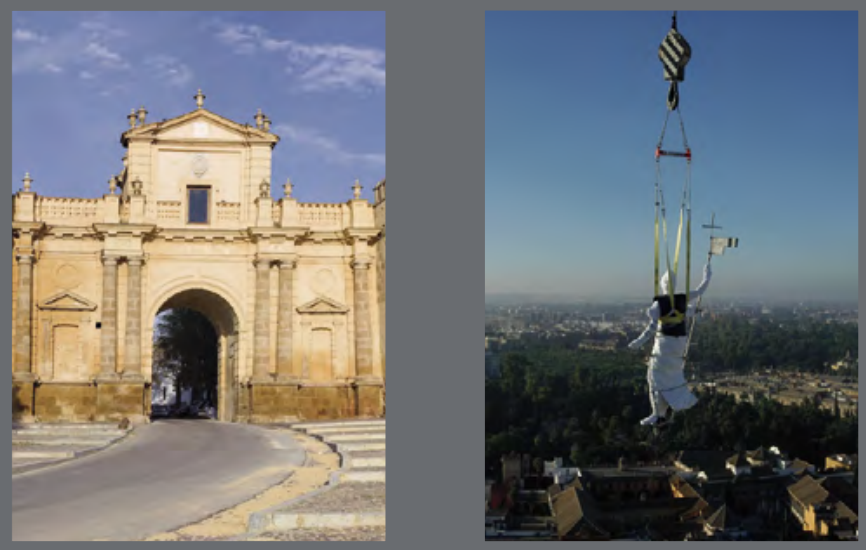

Puerta de Córdoba (Carmona) y Giraldillo, proyectos de restauración llevados a cabo por el IAPH. Foto Fondo Gráfico IAPH. 
1996). En Francia, alguien como Dominique Poulot advertía ya entonces de los riesgos de la desmaterialización de la noción de patrimonio, que se duplica con su desterritorialización, de forma que la labor de salvaguarda y registro se reemplaza por una empresa de revelación e interpretación (POULOT, 1997).

Se suceden los estudios que desarrollan algunos de sus aspectos, con Romero y Fernández Salinas, por ejemplo (CARAVACA BARROSO; COLORADO CAMPOS; FERNÁNDEZ SALINAS et al., 1997), mientras que se han marcado otras posiciones en la propia revista del IAPH (CASTILLO RUIZ, 1996; 2003), al tiempo que la Consejería refrenda la línea trazada en otro tipo de publicaciones (FERNÁNDEZ SALINAS; CARAVACA BARROSO; SÁNCHEZ DE LAS HERAS, 2005).

Si el territorio y la ciudad son el escenario donde las políticas culturales pueden ser factor de desarrollo, la arena cotidiana se hace espacio de conflicto, especialmente para algunas disciplinas. Es el caso de la arqueología, que se tecnifica con las experiencias sevillanas de Miguel Ángel Tabales, mientras la coyuntura urbana da pie a críticas (SALVATIERRA CUENCA, 1994a) sobre el denominado "modelo andaluz de arqueología" de los años ochenta (1985-1988), que entiende finalizado, en un periodo de transición para desarrollar una política arqueológica con la ciudad como marco en el que pueden crearse las bases para una nueva reflexión sobre las relaciones entre arqueología, protección y conservación, y ello a través de su consideración como un yacimiento único (SALVATIERRA CUENCA, 1994b). Concha San Martín ilustra el debate arqueológico del momento, desde otro ángulo, con la cuestión del museo como espacio de protección y difusión, en sendos artículos consecutivos en revista $\mathrm{PH}$ (SAN MARTÍN MONTILLA, 1994a; 1994b), un hecho que traslada luego al territorio, en línea con las nuevas expectativas de la moderna museología (SAN MARTÍN MONTILLA, 1998).

Otro escenario de planificación se va a producir en esos años. El IAPH construye un programa de formación con una batería de cursos que se complementa con los convenios firmados en 1995 con la Universidad de Sevilla para impartir títulos propios de máster, inicialmente Máster en Arquitectura y Patrimonio Histórico (MARPH), en Archivística (MARCH) y en Información y Documentación (MIDUS). Luego fueron acompañados por el dedicado a museos de la Universidad de Granada o el de gestión cultural, entre otros. Hoy en día solo continúa, y adaptado al Espacio Europeo de Educación Superior como título oficial, el Máster en Arquitectura y Patrimonio Histórico, de cuya larga evolución y de la problemática de formación de los técnicos en patrimonio la revista $\mathrm{PH}$ ha mostrado varios artículos a lo largo de su recorrido.

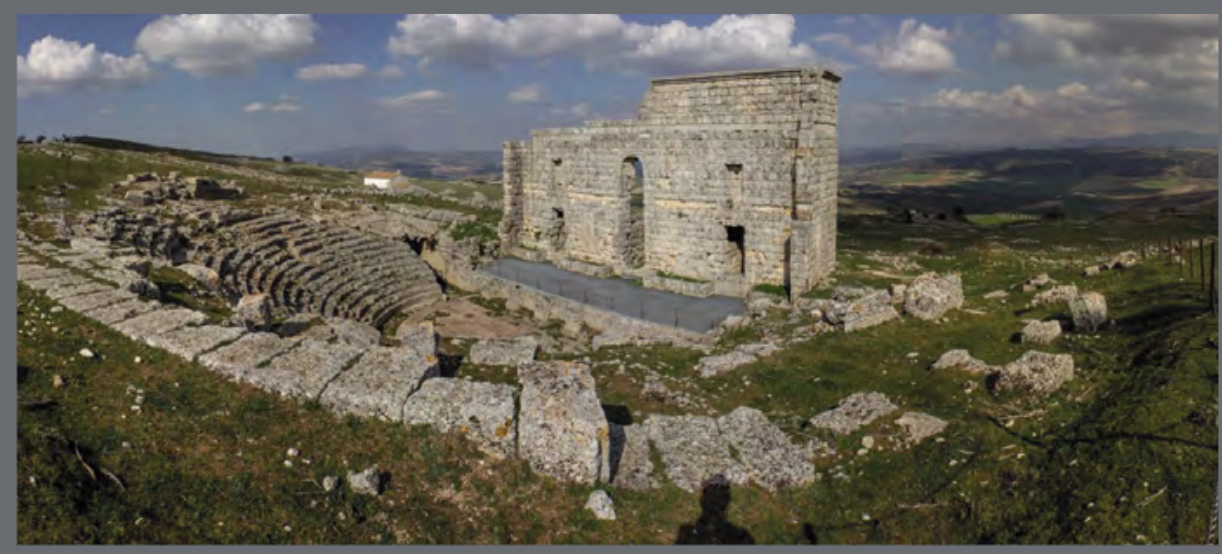

La restauración del teatro romano de Acinipo (Ronda) no solo consolidó un objeto. Aseguró la percepción de este enclave arqueológico, que hoy día propicia la comprensión de un paisaje cultural. Foto Eduardo Mosquera 
Pero debemos destacar de ese tiempo la aprobación parlamentaria del Segundo Plan General de Bienes Culturales. En este documento, el protagonismo de líneas marcadas por el IAPH emerge estructuradamente: la intervención desde la contextualización del objeto y otros modos de intervenir, del diagnóstico a la conservación preventiva; las prácticas de análisis, seguimiento e indicadores; la cuestión del plusvalor social y la necesidad de insertar los recursos patrimoniales en las estrategias y programas de desarrollo sostenible en el territorio; los agentes sociales en el territorio; museo y territorio; investigación, tecnología, cientificidad y creación, red de acciones, patrimonio inmaterial... De la época de la tabula rasa y el tiempo corto, inmediato, defendido durante casi cincuenta años, pasamos a la inflación patrimonial de lo contemporáneo que ya Françoise Choay denunció (CHOAY, 1992).

Al compás del nuevo PGBBCC 1996-2004 (aprobado en 1999), entre 1996 y 1997 el IAPH inicia sus jornadas de puertas abiertas y abre su página web. La articulación del IAPH y su Centro de Intervención se define claramente dentro del perfil de la revista $\mathrm{PH}$ demostrativo de la labor institucional (PÉREZ DEL CAMPO, 1996). Un nuevo centro se crea dentro del IAPH, el Centro de Arqueología Subacuática, en pleno proceso de apertura a los patrimonios "emergentes", que ya hemos indicado que tendrá su sede en un lugar emblemático, asimismo ${ }^{19}$. Será presentado en el editorial de revista $\mathrm{PH} 24$, de 1998. Pronto el debate añade en dicha revista cuestiones tutelares de relevancia (PÉREZ DEL CAMPO, 1999), que se toparán más adelante con casos notables, como el del pecio de Nuestra Señora de las Mercedes y la réplica a la actuación en 2007 de la empresa Odissey Marine Exploration.

Un nuevo estadio en la idea de planificación emerge con el Segundo Plan General de Bienes Culturales, que expone en $\mathrm{PH}$ el entonces viceconsejero Bartolomé Ruiz (RUIZ GONZÁLEZ, 1995). Dentro del Segundo Plan, el IAPH se mantiene como un plan instrumental. La explicación acabada de este instrumento la acoge $\mathrm{PH}$ de la mano de Guillermo López Reche, entonces jefe del servicio vinculado al Plan (LÓPEZ RECHE, 2004).

El impulso hacia una mayor proyección social de la tutela patrimonial es visto bajo el prisma de algunas revisiones críticas sobre el escenario general. Así, Ignacio Rodríguez Temiño indica en revista $\mathrm{PH}$ que "la cultura ha dejado de ser entendida como prestación social para entrar en el mundo del mercado como un producto de calidad para el consumo de élites, o trivializado para el masivo" (RODRÍGUEZ TEMIÑO, 1998) pero, al mismo tiempo, se promueve la idea de comunicación y de patrimonio accesible para todos (MORALES MIRANDA, 2001)
"La labor afrontada con la ensenada de Bolonia, que germina en una guía de su paisaje cultural, pondrá a punto una metodología que define la personalidad con la que el IAPH se formula en este tiempo, en cuanto a estructura de trabajo"

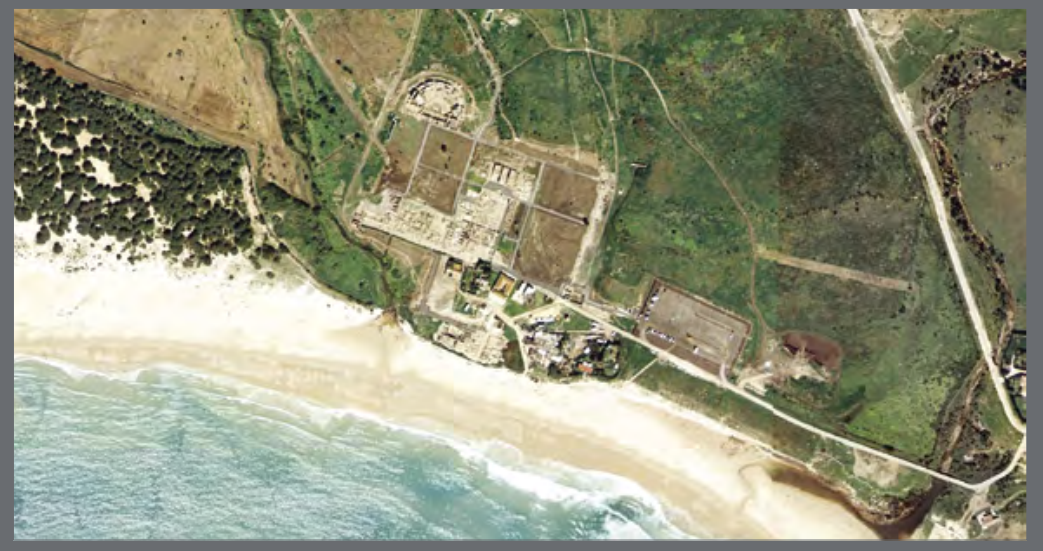

Acciones en el paisaje cultural de la

ensenada de Bolonia. Foto Jesús Granada 
El protagonismo de las personas conduce a retomar los temas etnológicos en revista $\mathrm{PH}$, abiertos a finales de los ochenta y en los trabajos de principios de los noventa. Los temas publicados en este sentido son muy numerosos, comprendiendo los relativos a la gestión tutelar, naturalmente (PLATA GARCÍA; RIOJA LÓPEZ, 2002), en un escenario en el que la Convención para la Salvaguardia del Patrimonio Cultural Inmaterial (2003) alimenta nuevas trayectorias, como más adelante reflejará el IAPH con el Atlas del Patrimonio Inmaterial de Andalucía.

Tras Capilla Real y los estudios iniciales de los leones de la Alhambra, tenemos los citados Santa Cueva, Puerta de Córdoba y otros proyectos donde definir un método, que en bienes muebles llega con pormenorizados estudios históricos y de caracterización (escultura, textil, metal, pintura, materiales arqueológicos y biológicos...), en un goteo incesante. Acontece en un tiempo en que la Consejería se mueve sobre la base de grandes operaciones de infraestructura cultural, con la consejera Carmen Calvo (1996-2004), de donde surge la Fundación Museo Picasso Málaga, Legado Paul, Christine y Bernard Ruiz-Picasso y la Fundación para el Legado Andalusí en el Corral del Carbón (PÉREZ YRUELA; VIVES, 2012).

El goteo consigue un alto impacto al producirse la restauración del Giraldillo, por el que el IAPH fue galardonado con el Premio Nacional de Restauración y Conservación de Bienes Culturales 2006, que otorgó el Ministerio de Cultura. Los proyectos marcan la evolución y el IAPH, con casos como el palacio de San Telmo, más recientemente con su colaboración en el desbloqueo del conflicto con Atarazanas Reales, determina los valores patrimoniales pertinentes para dar el correspondiente alcance a las intervenciones: el San Telmo de los mareantes y el de los Montpensier cobraron nueva vida con el IAPH en medio del rescate del edificio de la incuria a que lo abocó su uso como seminario y otros fines complementarios. Un debate en el que el IAPH acoge en 2006 a la III Bienal de Restauración Monumental (ACTAS, 2008).

Es el tiempo en que el ya citado Segundo Plan General de Bienes Culturales, conocido como Plan General de Bienes Culturales. Andalucía 2000, cumple su periodo de vigencia, cerrando el ciclo de ocho años de la consejera Carmen Calvo. En ese recorrido, el patrimonialista Javier Rivera valora el marco de las políticas culturales y los modelos de desarrollo, propiciando en la revista $\mathrm{PH}$ un protagonismo claro para instituciones como el IAPH (RIVERA BLANCO, 2001).

\section{Estudios territoriales multidisciplinares y la condición transversal de lo patrimonial}

Los planes generales, al margen de su nivel de cumplimiento, supusieron ocasiones por las que se pensó e hizo evolucionar el marco de la tutela, como hemos comentado. Finalizándose el Segundo Plan se plantea la cuestión del paisaje. En los años ochenta se produce una aproximación interdisciplinar al paisaje a partir del diálogo entre investigadores de las ciencias naturales y sociales, con una voluntad de devolver el paisaje a las personas y a lo social frente a las aproximaciones biológicas. El paisaje está por todos lados y se encuentra comprendido en el marco banal de la vida cotidiana. El IAPH en 2004 se encuentra ya incorporado decididamente, pues a partir de la redacción del Convenio Europeo del Paisaje (2000) se tiene el horizonte de su entrada en vigor en España el 1 de marzo de 2008. El paisaje se entiende entonces que puede desbloquear el futuro de los territorios, con el hilo de un diálogo social. Cuando las políticas han obligado a construir subjetividades, la idea de paisaje concertado se convierte en expresión visible de un pacto simbólico pasado entre los hombres y con el territorio (BRIFFAUD, 2003).

La visión territorial del patrimonio adquiere un innovador vector de calidad que es el del paisaje y su tutela, en términos de paisaje cultural. Un primer seminario, Territorio y Patrimonio. Los paisajes andaluces (octubre de 2001, IAPH-Sevilla), aborda ya este punto de vista y deriva en la publicación homónima del IAPH (FERNÁNDEZ LACOMBA; ROLDÁN CASTRO; ZOIDO NARANJO, 2003), donde destacamos el capítulo de Pedro Salmerón "Paisaje y patrimonio cultural", mientras que el territorio sigue dando paso a nuevas y numerosas contribuciones en revista PH (VERDUGO SANTOS, 2005). Algunas entregas de $\mathrm{PH}$ constituyen monográficos multidisciplinares, muchas de ellas lo hacen destacando la componente productiva del tejido social local y la transversalidad de lo patrimonial, que han marcado un antes y un después en la consideración de amplios escenarios andaluces: por ejemplo, la entrega de revista PH 28 (1999), Especial Monográfico: DO.CO.MO.MO., que marca el origen del compromiso del IAPH con el patrimonio contemporáneo con el impulso de Víctor Pérez Escolano, cuestión también presente en otros números ${ }^{20}$; la entrega de revista $\mathrm{PH} 44$ (2003), con el Especial Monográfico: Patrimonio pesquero; o la problemática de la gestión territorial en revista PH 60 (2006), en el Especial Monográfico: Itinerarios y rutas culturales. 
Los trabajos del IAPH en este sentido ${ }^{21}$ fructifican en guías que serán los principales referentes metodológicos, numerosos estudios y la constitución del Laboratorio del Paisaje.

La labor afrontada con la ensenada de Bolonia, que germina en una guía de su paisaje cultural, pondrá a punto una metodología que define la personalidad con la que el IAPH se formula en este tiempo, en cuanto a estructura de trabajo, retomando, como en otras ocasiones, la coordinación con el arquitecto Pedro Salmerón, ya vivida en planes generales previos (SALMERÓN ESCOBAR, 2004). Se plantearán diversos trabajos al hilo del modelo definido en la guía, entre los cuales varios tienen eco en revista $\mathrm{PH}$ y otros medios como el Instituto de Patrimonio Cultural de España (FERNÁNDEZ-BACA CASARES; CASTELLANO BRAVO; FERNÁNDEZ CACHO et al. 2007; FERNÁNDEZ-BACA CASARES; GARCÍA DE CASASOLA GÓMEZ; CASTELLANO BRAVO, 2014), abarcando las escalas y los tiempos, la materialidad y el patrimonio inmaterial, dando pautas de gestión interinstitucional, para un territorio que había vivido no pocas tensiones que ponían en riesgo sus atributos culturales y naturales. La administración de lo cultural y de lo natural convergen dentro de la cualidad de transversalidad que el tratamiento del paisaje otorga al patrimonio. Mientras, el IAPH también se ha involucrado en la problemática del turismo cultural y su dimensión de sostenibilidad ${ }^{22}$ en revista $\mathrm{PH} 36$ (2001): Especial Monográfico: Turismo en ciudades históricas.

Estos esfuerzos están dentro de un nuevo rumbo en las políticas sobre los bienes culturales que culminan en un cambio en el marco legislativo, y en el propio estatus jurídico del IAPH, que se abre a nuevos patrimonios, siguiendo la tendencia indicada que arrancó en los años noventa. De hecho, la propia revista PH aborda puntualizaciones como las de María Morente sobre el concepto de patrimonio cultural (MORENTE DEL MONTE, 2006) y previamente se ha avanzado en la problemática de criterios de intervención con un significativo monográfico dedicado a la restauración, que reafirma al Centro de Intervención y aporta desde una plural arena exterior una importante riqueza de pronunciamientos ${ }^{23}$.

\section{Una posición renovada}

Este nuevo tiempo se ve marcado por el cambio que experimenta el IAPH, mediante la Ley 5/2007, de 26 de junio, por la que se crea como entidad de derecho público el Instituto Andaluz del Patrimonio Histórico, con dos decretos adicionales de adaptación y modificación ${ }^{24}$. Pasamos de la creación al desarrollo y consolidación de la estructura, con la adquisición de una mayor autonomía, como muestra de competitividad. Las tareas compartidas de la tutela se conducen a nuevos agentes con más agilidad y su articulación con el I+D+i confieren otro estatuto al IAPH, desde la idea de innovación y excelencia en las prácticas patrimoniales.

Se suman concentradamente, en la línea de disposiciones legales, otras nuevas situaciones, claramente transcendentales en el ámbito tutelar. Poco después se promulga la Ley 8/2007, de 5 de octubre, de Museos y Colecciones Museográficas de Andalucía y la vigente Ley 14/2007, de 26 de noviembre, del Patrimonio Histórico de Andalucía, que es la segunda del ordenamiento andaluz, tras la Ley 1/1991, de 3 de julio, de Patrimonio Histórico de Andalucía. Otros patrimonios e instituciones tienen que esperar a 2011 para completar el relevo, caso de la Ley 7/2011, de 3 noviembre, de Documentos, Archivos y Patrimonio Documental de Andalucía.

Es un tiempo en que Maurizio Fagiolo dell'Arco clama en la mismísima Italia respecto a los museos y otras infraestructuras culturales, ante tantas ocasiones perdidas, silencios piadosos, censuras imprevisibles... cuando las estructuras estatales o los entes locales llenan de obstáculos el camino de los que quieren comprender el hoy y las formas del ayer, para así individualizar una posible idea de convivencia futura (SOUTIF, 2007).

La Ley 14/2007, de 26 de noviembre, además de reformar el marco de las instituciones y espacios culturales, creando la RECA (Red de Espacios Culturales de Andalucía), aporta nuevos patrimonios a las tipologías jurídicas, donde aparecen el lugar de interés industrial, ya finalmente reconocido como tal aparte de la fórmula de incluir el patrimonio industrial dentro de los lugares de interés etnológico, entre otras tipologías previas, y aportando como novedad mayor la definición de la zona patrimonial.

Esta figura, y la revisión del tratamiento urbanístico y territorial de la tutela, han producido numerosos estudios. La ley fue pronto evaluada por juristas y otros técnicos desde dentro (LÓPEZ RECHE, 2008). Se realizaron asimismo trabajos en relación con la relevancia que adquiere la instrumentación y gestión urbanística (BECERRA GARCÍA, 2010), retomando una línea abierta en revista $\mathrm{PH}$ en 2000 (BECERRA GARCÍA, 2000), también desde la universidad (BARRERO RODRÍGUEZ, 2007; 2012; CASTILLO RUIZ, 2009). Una trayectoria matizada para el patrimonio arqueológico y lo urbano con 


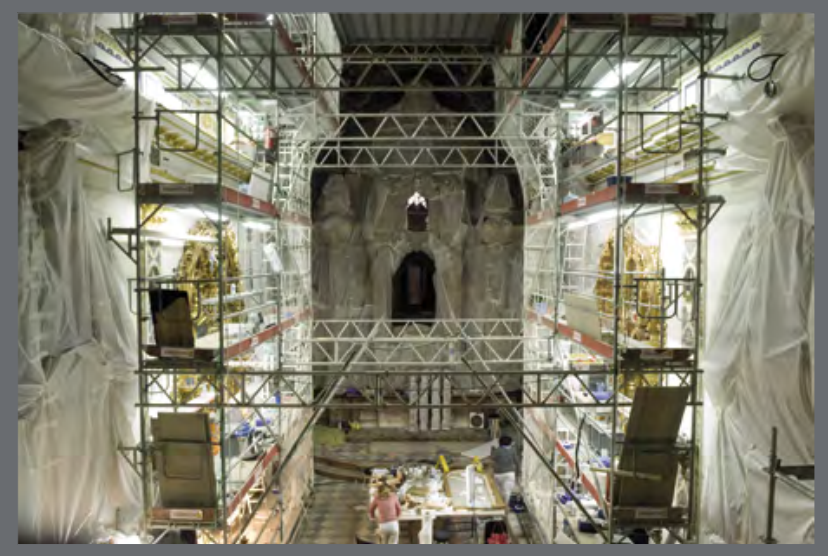

"La articulación del IAPH y su

Centro de Intervención se define

claramente dentro del perfil de

revista PH demostrativo de la

labor institucional"

Proyecto de intervención del IAPH de los bienes culturales de

Palacio de San Telmo. Foto Fondo Gráfico IAPH

anterioridad (RODRÍGUEZ DE GUZMÁN SÁNCHEZ, 2005) y ahora complementada con otros puntos de vista (FERNÁNDEZ CACHO, 2008), trabajos ambos especialmente valorados por Ángeles Querol en un relevante libro (QUEROL, 2010). Conviene destacar, tras la Ley 14/2007, el análisis sobre el planteamiento de las zonas patrimoniales, caso de la letrada de la Junta de Andalucía Mónica Ortiz y sus complejos análisis jurídicos (ORTIZ SÁNCHEZ, 2010; 2011), o de Javier Verdugo en línea con su gestión (VERDUGO SANTOS, 2010).

Si lo industrial, ya como patrimonio industrial con título propio en la nueva ley, acompaña separadamente a lo etnológico, algunos piden a continuación otro estatus para el patrimonio del mundo agrario, como la Carta de Baeza sobre patrimonio agrario (CASTILLO RUIZ, 2013), un redundante testigo de no pocos conflictos patrimoniales históricos, como la vega de Granada, en ocasiones resuelto - hasta la fechapor la vía de las zonas patrimoniales, como también ha sido el caso de algunas comarcas mineras. En esta línea, el número 74 de revista PH (2010) definió un conjunto de relevantes aportaciones al caso granadino.

En este sentido, conviene señalar que en la dinámica vivida con la Ley 14/2007 y demás disposiciones, se pasa de la redacción de los planes generales como suma de programas y planes sectoriales a la figura del plan estratégico, ligada a la visión omnicomprensiva de las políticas culturales. Llegados a este punto conviene indicar que un plan estratégico será el siguiente documento que conceptualiza e instrumenta la tutela patrimonial: el PECA (Plan Estratégico para la Cultura en Andalucía 2008-2011), que se inicia en 2004, se aprueba en 2007 con la consejera Rosario Torres, pero no se remite al Parlamento. En él se previó un programa de bienes culturales con siete objetivos específicos, todos ellos ajustados a las tareas tanto de la dirección general como del IAPH (para este último más exclusivamente el de "Formar en patrimonio histórico y gestión cultural"), que tuvo un especial protagonismo en un documento que movilizó a innumerables personas. A los objetivos de bienes culturales, se sumaba como novedad la Red de Espacios Culturales de Andalucía (RECA), que establece la coetánea Ley $14 / 200725$. Pero es el momento en que aparecen los planes directores claramente imbricados con bienes culturales esencialmente complejos, con una gestión muy cualificada y la necesidad de tutela muy clara, aunque sin efectos económicos directos. Así lo establece dicha Ley en su artículo 79, "Funciones de los Conjuntos"26.

\section{El contexto de la crisis sufrida desde 2008} en adelante conduce en un primer término a reflexionar sobre el alcance de estos planes, pero conviene destacar que el Plan Director de la Alhambra fue aprobado por el Pleno del Patronato y publicado en 2010, con vigencia 2007-202027, 
mientras que el correspondiente a Itálica se formuló en nivel de Avance revisado en 2011, dotándose de cinco estrategias y diez programas ${ }^{28}$, sumándose el Avance del Plan Director del Conjunto Arqueológico de Madinat al-Zahra ${ }^{29}$, dentro del periodo del consejero Paulino Plata. En esta línea, decir que en mayo de 2018 se ha aprobado el Plan Director del Sitio de los Dólmenes de Antequera, por lo tanto, los planes se redactan generalmente para conjuntos inscritos en la Lista de Patrimonio Mundial, a excepción de Itálica, que presumimos como un próximo y válido aspirante.

\section{Nuevas perspectivas, a propósito del paisaje y la gestión de los recursos culturales del territorio}

Mientras, el cambio legal y las puertas abiertas que comentamos otorgan otra perspectiva de análisis, que siempre debe ser continuo, al recorrido ya trazado de las políticas culturales en Andalucía (ROMERO MORAGAS, 2008). La relación entre patrimonio y territorio sigue abordándose tras la nueva ley de patrimonio desde la gestión de la información y la investigación para su protección en numerosos estudios de diverso eco (MARTíNEZ YÁÑEZ, 2008; MUÑOZ CRUZ, 2014; MONTUFO MARTÍN, 2017).

Por una parte, conviene recordar la labor enciclopédica de caracterización de paisajes de Andalucía coordinada por Víctor Fernández
Salinas, entre otros (FERNÁNDEZ CACHO; FERNÁNDEZ SALINAS; HERNÁNDEZ LEÓN, 2010). $Y$ que se acompaña del registro definido, del que en revista $\mathrm{PH}$ se tienen ya recientemente factores de análisis pormenorizado (FERNÁNDEZ CACHO; FERNÁNDEZ SALINAS; RODRIGO CÁMARA et al., 2015) y bases conceptuales revisadas en el Laboratorio del Paisaje del IAPH y ante la Estrategia de Paisaje de Andalucía (FERNÁNDEZ CACHO, 2014; ACOSTA BONO; FERNÁNDEZ CACHO; FERNÁNDEZ-BACA CASARES, 2017).

Por otra, el planteamiento de evaluación, para rescatar el tratamiento del paisaje de la discrecionalidad, con la idea de indicadores, de sostenibilidad, de viabilidad de la calidad que está en los estudios de ciudades históricas. En particular destacaremos las aproximaciones a las americanas, inscritas en la Lista de Patrimonio Mundial (FERNÁNDEZ-BACA CASARES; SALMERÓN ESCOBAR; SANZ, 2009; 2011). El paso siguiente es la elaboración de una Guía del paisaje histórico urbano de Sevilla, con el referente del Memorándum de Viena y la llegada de la arquitectura contemporánea a determinados contextos. En el caso de Sevilla, se incide en una parafernalia de proyectos con indicadores en una ciudad que se ha tambaleado en su percepción del paisaje con la torre Pelli, ahora torre Sevilla. Con estos estudios de paisaje el IAPH persiste en la idea de guías (Bolonia, paisaje histórico urbano de Sevilla), de documentos técnicos que
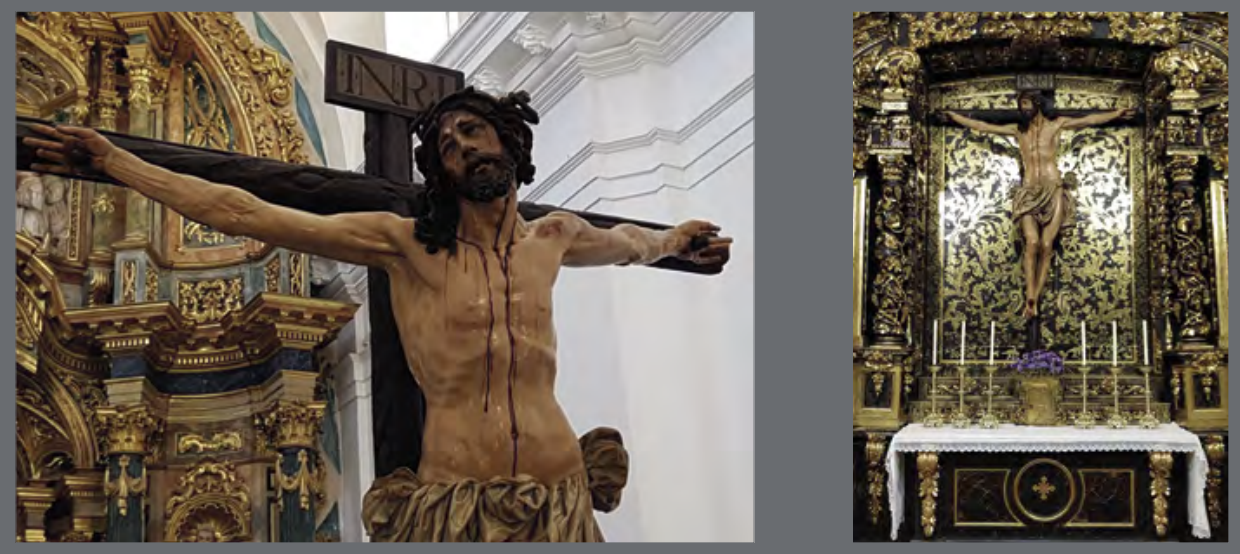

El Cristo de la Agonía, obra de Juan de Mesa, fue invervenido por el IAPH en 2017 y posteriormente devuelto a la parroquia de San Pedro de Ariznoa en la localidad de Bergara (Guipúzcoa). Fotos Eduardo Mosquera 
son las bases para una estrategia de proyectos que recualifique el modelo de gestión tutelar. Así, la Guía del Paisaje Histórico Urbano de Sevilla (FERNÁNDEZ-BACA CASARES; FERNÁNDEZ CACHO; SALMERÓN ESCOBAR, 2017) "persigue incrementar el conocimiento de este instrumento, desarrollado por el IAPH entre 2008 y 2015 para orientar los cambios en la ciudad desde la perspectiva de una evolución y crecimiento compatible con el mantenimiento de sus valores naturales y culturales".

La problemática del paisaje cultural, en que ICOMOS con el caso de Sevilla fue especialmente activo, entra en el terreno de la percepción de las cosas, cuando se valoran signos y símbolos a la vez en el seno del espacio mundial globalizado por la mercancía y en diversas escalas subnacionales o supranacionales, testimoniando en cierto modo nuestro relativismo cultural. La exportación de la noción de patrimonio conducida en la esfera internacional tiene como consecuencia, según Dominique Poulot, que el inventario de los patrimonios culturales de la humanidad en el espacio y el tiempo sustituye al canon tradicional de la civilización surgida de la llustración (ANDRIEUX, 2011), con las repercusiones que implica.

\section{La acción directa}

sobre los bienes culturales

La Carta de Cracovia (2000). Principios para la conservación y restauración del patrimonio construido plantea, entre otras, cuestiones sobre la autenticidad, ya abierta con la Carta de Nara de 1994, y sobre todo la necesidad del conocimiento para intervenir, que el IAPH hace suyas.

En este sentido, Marco Dezzi Bardeschi ha señalado que el dominio de la autenticidad no está solo en la materia, hay que dialogar con otras culturas, escrutar con profundidad, desde un proyecto de respeto, salvaguarda, conservación, puesta en valor, no a las grandes restauraciones y sí al proyecto de conocimiento. La obra es algo abierto al futuro, no bloqueada, reconociéndose la identidad de todas las aportaciones, de todas las estratificaciones, de todas las manos (DEZZI BARDESCHI, 2004). Mientras que Jokilehto ha subrayado el proceso de desarrollo de los principios de conservación con especial énfasis en autenticidad e integridad y el cambio de los aspectos materiales a los intangibles en patrimonio (JOKILEHTO, 2009), cuando ya la Carta de Venecia en 1964 marcaba la importancia de la integridad histórica (artículos 11, 12 y 14). En el contexto de patrimonio mundial ha emergido la idea de condición de integridad, para lo natural y en 2005 para lo cultural y sus atributos, a fin de asegurar la completa representación de temas y procesos que implica su significado, indica dicho autor.

El problema de la integridad y la autenticidad se produjo con la experiencia ya comentada de San Telmo. Los informes de valoración patrimonial, publicados en revista PH 51 (FERNÁNDEZ-BACA CASARES; LLEÓ CAÑAL; MOSQUERA ADELL et al., 2004), que dieron vía a la intervención arquitectónica de San Telmo (culminada en 2010), han sido considerados claves para el ámbito jurídico en la solución de la recuperación de San Telmo (TORRES RIDRUEJO, 2012), formando parte de uno de los análisis de las dinámicas patrimoniales, el judicial, que recogió la revista PH 82 en 2012, con su Especial monográfico: Patrimonio y tribunales de justicia.

De hecho, la ejemplar restauración y puesta en valor de la capilla (2005-2009) por parte del IAPH, entre otras labores en dicho bien cultural, ha significado que en 2014 se haya otorgado la encomienda de gestión por parte de la Consejería de Presidencia al Instituto Andaluz del Patrimonio Histórico (IAPH) para el asesoramiento integral técnico sobre la conservación y puesta en valor de su sede, el Palacio de San Telmo de Sevilla, y de su colección artística.

El IAPH desarrolla dentro de estas preocupaciones un amplio espectro de intervenciones en el recorrido en continuidad que comentamos, del que la revista $\mathrm{PH}$ expone procesos y aporta resultados, imposibles de sintetizar aquí, pero cumple comentar - por cerrar este apartadoexperiencias como la del retablo de Santa Ana de Triana (PÉREZ CANO; PÉREZ DEL CAMPO; VILLANUEVA ROMERO et al., 2011).

\section{Un nuevo marco legal y otra realidad administrativa: la ruta del IAPH como agencia hacia la investigación y la excelencia, en un inestable escenario de planificación}

Tras el PECA, en el periodo 2010-2012 se reformula la práctica de la planificación. Se produce el Acuerdo de 27 de septiembre de 2011, del Consejo de Gobierno, por el que se aprueba la formulación del sistema de planificación de políticas culturales de la Junta de Andalucía, con la característica verticalidad de planes pasados y un nuevo PGBBCC ${ }^{30}$. Se abre así la vía al III Plan General de Bienes Culturales ${ }^{31}$, aprobado el 1 de abril de 2012. Fue un plan "elaborado con la aportación directa de los gestores de la tutela del patrimonio cultural, tanto de los servicios centrales de la Consejería de Cultura como de los provinciales. Este documento de trabajo se ha dotado de un contenido argumental suficiente 
para que sirva de base a los próximos procesos de análisis y reflexión que permitirán conformar el documento definitivo". Un nuevo proceso electoral en marzo de 2012 interrumpe esa dinámica, en la que se valoraba que "la estrategia de integridad de la tutela que propugnaba el Plan General de Bienes Culturales, Andalucía 2000 no ha tenido un avance significativo... los planes sectoriales desarrollados -Plan de Arquitectura Defensiva de Andalucía (PADA), Red de Espacios Culturales de Andalucía (RECA) y Andalucía Barroca 2007- han contribuido en distinta medida a este fin"32.

En el Tercer Plan se produce una Aproximación conceptual a la tutela del Patrimonio cultural que se centra en "la ordenación del uso social de los bienes, una necesidad más reciente con la complejidad y demanda actual, tiene un desarrollo conceptual, una experiencia de gestión y una regulación jurídica menos desarrollada y, como consecuencia, ocupa un espacio más reducido en el organigrama administrativo, a pesar de que constituye un problema desafiante y creciente en la tutela. El avance de las investigaciones sobre el uso social del patrimonio cultural, su reconceptualización y el desarrollo de políticas culturales es, en este sentido, del todo necesario. Y conviene desarrollar los procesos transversales de gestión del conocimiento, comunicación y gobernanza".

Solo un año después, sin que este III PGBBCC se haga operativo, el 11 de abril de 2013, agentes culturales, económicos y sociales andaluces y el Gobierno de Andalucía firman el Pacto por la Cultura en Andalucía, como una alianza entre el patrimonio andaluz, la ciencia y la investigación, la ordenación y gestión del territorio andaluz, incluyéndolo en los instrumentos de planificación urbana y territorial, así como en la puesta en valor del patrimonio urbano como seña de identidad de nuestra Comunidad y de los paisajes culturales a través de la creación de una marca de calidad con la que reconocer las buenas prácticas en el patrimonio andaluz y la salvaguarda del patrimonio inmaterial. Respecto a las instituciones culturales y museísticas, se hace referencia a cambios en el modelo de gestión en relación con otros agentes públicos y privados. No obstante, cabe decir de la limitación de la estructura de agentes sociales en el territorio de la que se dispone, y las dificultades para implicar más a nuevos tejidos, ante un patrimonio tan extenso y complejo como el andaluz.

En esta línea, el IAPH se ha actualizado como agente y ha producido acciones y numerosos documentos técnicos. En coherencia con el trabajo sobre el paisaje cultural, lo ha hecho en forma de recomendaciones relativas tanto a su documentación como a la necesaria participación social ${ }^{33}$.

Nos encontramos precisamente ahora en la coyuntura de la Modificación de la Ley 14/2007, en la que se plantea introducir una subtipología para el paisaje de interés cultural. Solo corresponde añadir que la idea de planificar la acción sobre los bienes culturales continúa su recorrido evolutivo. El 10 de julio de 2018, el Consejo de Gobierno de la Junta de Andalucía ha acordado iniciar la elaboración del Plan Estratégico de Bienes Culturales y Museos de Andalucía, con una duración cuatrienal. El acuerdo indica que este instrumento se pondrá en relación con la modificación indicada de la vigente Ley 14/2007, centrándose en la aplicación de políticas de apoyo a la participación ciudadana y a las alianzas con los agentes culturales, de mejoras administrativas que incluyen nuevas atribuciones a las corporaciones locales, la optimización de los recursos públicos destinados a la gestión cultural y el cumplimiento de los compromisos derivados de la ejecución de los fondos de la Unión Europea.

En esa atmósfera de planificación estratégica, el propio IAPH redactó un Avance del Plan Estratégico 2012-2015, donde se abunda en el hecho de que "la noción de patrimonio se encuentra en permanente estado de transformación debido a que el patrimonio es una construcción social: son las sociedades y sus miembros las que elaboran sus expresiones culturales y las que deciden cuáles de las que han llegado hasta el presente desean proteger y conservar. Desde el punto de vista de la gestión patrimonial se ha evolucionado desde el concepto de tutela hacia el de políticas culturales, donde la gestión está basada en la complementariedad de instituciones y agentes presentes en el territorio y en estrategias más amplias de desarrollo"34.

Documentos como el Plan Anual 2017 de previsión de actuaciones del IAPH ${ }^{35}$ o la Memoria anual 2016 del IAPH ${ }^{36}$ no hacen sino confirmar estas posiciones y líneas de actuación. Por ejemplo, los trabajos recientes del Centro de Documentación y Estudios ${ }^{37}$, alguno publicado en revista $\mathrm{PH}$ (FERNÁNDEZ CACHO; ARENILLAS TORREJÓN; MONDÉJAR FERNÁNDEZ DE QUINCOCES et al., 2017).

La decidida apuesta del Instituto Andaluz del Patrimonio Histórico en sus más de 25 años de trayectoria por la investigación científica y técnica de excelencia ha conducido a su registro oficial como agente del Sistema Andaluz del 
"La revista PH, en este sentido, es más que un observatorio y una plataforma, es testimonio privilegiado de la orientación del quehacer patrimonial desde Andalucía. Su primer cuarto de siglo augura evoluciones aún más productivas"

Detalle de los baños de Comares en la Alhambra de Granada, restaurados por el Patronato de la Alhambra y Generalife con Pedro Salmerón en 2016. Sus características y sus necesidades de conservación impiden el acceso convencional a los visitantes dentro del bien cultural más visitado de Andalucía. Se integra en la comprensión de conjunto mediante técnicas de difusión tanto tradicionales como avanzadas. Foto Eduardo Mosquera

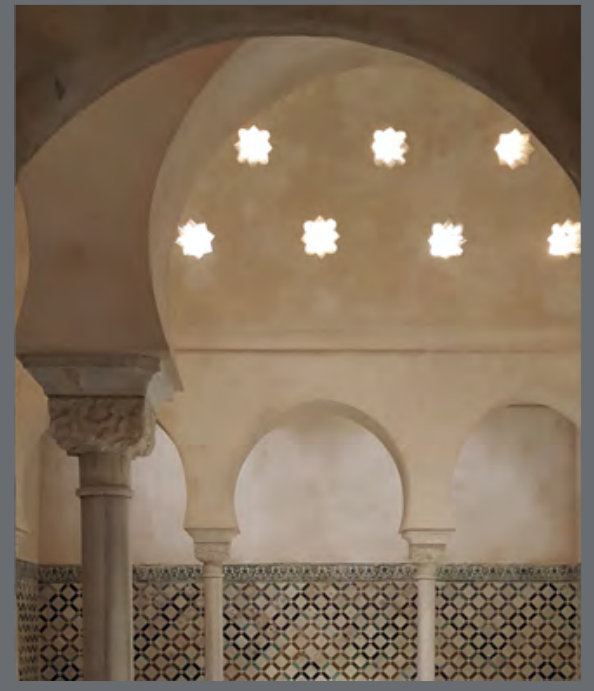

Conocimiento, en la clasificación concreta de instituto de investigación, según se recoge en sus documentos. El IAPH se encuadra en el grupo de los denominados "agentes de generación del conocimiento". Lo encontraremos así, como proveedor de servicios en cuanto agencia pública, como unidad de cultura y como agente del Sistema Andaluz de Conocimiento, de modo que también es un instituto de investigación, un laboratorio de patrimonio y una escuela de patrimonio.

Los programas de actuación 2017-2020 del IAPH, en cuanto proyección de futuro, insisten en la mediación entre ciencia pública, patrimonio cultural y otras políticas sectoriales; en la normalización metodológica y recomendaciones científicas y técnicas de aplicación al patrimonio cultural; asistencias técnicas y servicios especializados; innovación en la gestión del patrimonio cultural; posicionamiento en I+D+i; conocimiento en abierto; cultura científica;

formación y capacitación de especialistas: escuela de patrimonio cultural; LAP. laboratorio abierto de patrimonio y excelencia en la gestión.

En esta línea, la aproximación a la investigación desde el IAPH y la Dirección General de Bienes Culturales ha determinado la realización de tesis doctorales, por parte de significadas personas que han cumplido el recorrido de la tutela que se comenta, como desde el ámbito de la protección
(BECERRA GARCÍA, 2017; PLATA GARCÍA, 2017), $y$, en general, de la tutela (FERNÁNDEZ-BACA CASARES, 2017), añadiendo un inapreciable cuadro de aportaciones que clarifica la evolución experimentada y la complejidad que media entre formulación y praxis en el trabajo patrimonial.

Si consideramos algunos referentes hacia adelante en Andalucía que acompañan a la Dirección General de Bienes Culturales en su esfuerzo organizador de la gestión tutelar, podemos centrarnos en la capacidad ejecutiva del Patronato de la Alhambra, hasta ahora dirigido sucesivamente por Mateo Revilla, María del Mar Villafranca y actualmente por Reynaldo Fernández Manzano, que nos obliga a seguir la factibilidad de su Plan Director (2007-2020) y la oportunidad que representa la reforma de sus estatutos, o para el ámbito del conocimiento, el despliegue de la Escuela de la Alhambra, dirigida por Manuela Reina. El IAPH, con sus programas de actuación 2017-2020 a idéntico término, y la experiencia acumulada al compás de la evolución del concepto de tutela, su gestión y planificación, afronta ahora un tránsito a una nueva dirección por la marcha de Román Fernández-Baca a la Administración estatal, tras 29 años con dicha responsabilidad, y que ahora recoge Lorenzo Pérez del Campo.

Entendemos que para el IAPH resulta altamente específico estructurar la idea de tutela con un modelo de gestión por proyectos que obligan 
"El referente del IAPH no tiene más que progresar. Para ello, es conveniente asumir la conveniencia de liderar proyectos de investigación según intereses del marco europeo, la internacionalización de la producción de sus investigadores y técnicos y una revista PH que incluya el inglés"

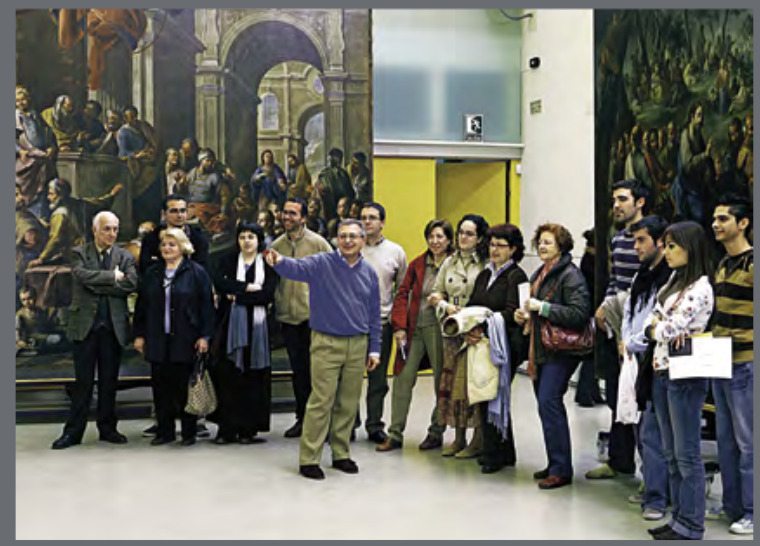

Visita guiada en el taller de pintura del IAPH. Foto Fondo Gráfico IAPH a la investigación, a una forma de gestión del conocimiento más avanzada y compartida. Por ello, difusión y comunicación, más formación, se hacen especialmente relevantes. El enjambre de títulos oficiales de grado, máster y doctorado, relacionados con los resultados del Proceso Bolonia, requieren una posición de referencia, en la que la continuidad de décadas del Máster en Arquitectura y Patrimonio Histórico con el IAPH y el Patronato de la Alhambra ha servido para racionalizar algunas de las cuestiones derivadas de esa eclosión.

Pero la tarea del nuevo diseño cooperativo del mapa de agentes en el territorio (más allá de las sabidas fundaciones, entidades financieras, cofradías y asociaciones) está por realizarse, donde el necesario papel de las ciudades medias de Andalucía puede recomponer el sistema patrimonial apoyado en los grandes destinos culturales y turísticos.

La reciente experiencia de las Atarazanas Reales de Sevilla y la relación con lecturas diversas de la legislación patrimonial y la búsqueda de acuerdos reclama respuestas desde el conocimiento cada vez más eficaces y exigentes, ante los presumibles conflictos derivados de la sociedad civil y la judicialización de no pocas discrepancias en la arena patrimonial. En este sentido, el referente del IAPH no tiene más que progresar. Para ello, es conveniente asumir la conveniencia de liderar proyectos de investigación según intereses del marco europeo ${ }^{38}$, la internacionalización de la producción de sus investigadores y técnicos y una revista $\mathrm{PH}$ que incluya el inglés.

El historiador Pierre Nora ha indicado que el patrimonio de hoy obedece a otro tipo de relaciones con el pasado, extremadamente fuertes, casi obsesivas, un hecho que tiene sus ventajas y sus inconvenientes, pero ante el que hay que tomar la situación como tal. La revista $\mathrm{PH}$, en este sentido, es más que un observatorio y una plataforma, es testimonio privilegiado de la orientación del quehacer patrimonial desde Andalucía. Su primer cuarto de siglo augura evoluciones aún más productivas. 
${ }^{1}$ Esta nueva etapa comenzó con un editorial titulado "Más atractiva y cercana".

2 Fueron 7 números, de diciembre de 2013 a diciembre de 2016. En 2017 se crea en revista $\mathrm{PH}$ una sección de "Investigación" que la sustituye y que asume la línea de exigencia de revisión por pares externos a ciegas del extinto proyecto.

${ }^{3}$ Reformulados en 2005, se abrieron a la producción en formato digital en 2009.

${ }^{4}$ Más adelante se sustituirá por la Ley 16/2003, de 22 de diciembre, del Sistema Andaluz de Bibliotecas y Centros de Documentación.

${ }^{5}$ En menos de un año se promulgaron la Ley 2/1984, de 9 de enero, de Museos y la Ley 3/1984, de 9 de enero, de Archivos. Más tarde se crea, según previsión de esta última, el Archivo General de Andalucía (Decreto 323/1987, de 23 de diciembre).

${ }^{6} \mathrm{~A}$ resaltar que ya emerge en aquella época la cuestión del paisaje.

${ }^{7}$ Para el caso de Andalucía, nos encontramos con las cuevas, abrigos y lugares que contengan manifestaciones de arte rupestre (Ley 16/1985, art. 40.2), los inmuebles destinados a la instalación de archivos, bibliotecas y museos de titularidad estatal, así como los bienes muebles integrantes del patrimonio histórico español en ellos custodiados (Ley 16/1985 art. 60.1); también, los castillos, escudos, emblemas, piedras heráldicas, rollos de justicia, cruces de término y piezas (Ley 16/1985, disposición adicional segunda).

${ }^{8}$ También se efectuaron referencias a bienes muebles, en un momento de incipiente desarrollo de sus figuras.

${ }^{9}$ Se trata del Decreto 59/1986, de 19 de marzo por el que se aprueban los Estatutos del Patronato de la Alhambra y Generalife.

${ }^{10}$ Fue uno de los cuatro programas especiales del Plan, junto con el del Archivo General de Andalucía, el Conjunto Monumental de la Alhambra y Generalife y el Conjunto Monumental de la Cartuja de Sevilla.

"El armazón conceptual tiene su fundamentación general en trabajos genéricos sobre patrimonio y cultura producidos en escenarios variopintos, como el mundo norteamericano (LOWENTHAL, 1985), latinoamericano (GARCÍA CANCLINI, 1990) o desde Francia (CHOAY, 1992) -tras las aportaciones de historiadores como Jacques Le Goff, Pierre Nora... o pensadores como Michel Foucault-, en un tiempo sumamente ecléctico, cuando no relativista, en el que el pensamiento crítico se combina con el pensiero debole y las formulaciones de la denominada posmodernidad, al tiempo que la hermenéutica se renueva como vía para poner a las personas ante la producción cultural, y la sociología, de la mano de Manuel Castells, Anthony Giddens, Pierre Bourdieu y tantos otros, cobran un particular protagonismo.

${ }^{12}$ En simultáneo, para nutrir ese ámbito de actuación, en esos años se encontrarán disponibles innumerables trabajos recién producidos desde la factoría italiana sobre conservación y restauración, que sumar a la esfera jurídica y de la protección: para los bienes muebles (CONTI, 1988) y para los inmuebles (FEIFFER, 1989), (BELLINI, 1990), (CARBONARA, 1990), MARCONI, 1993), luego con algunos realmente "monumentales" (CARBONARA, 1996). Sin olvidar en la órbita francesa, por ejemplo, la cuestión de la museología, el patrimonio local, el medio ambiente y el desarrollo, con Hughes de Varine-Bohan, André Desvallées o Georges-Henri Rivière (WEIS, 1989). En España se inicia una encomiable labor de difusión de estudios patrimoniales extranjeros (Lowenthal, Rivière, Choay) y españoles (Ballart, Querol, Rivera...) a partir de esos años ochenta y noventa, por parte de algunas administraciones y de editoriales como Akal o Comares, con la figura de Juan Calatrava como impulsor de no pocas iniciativas en este sentido

${ }^{13}$ En el marco de dicho curso se hizo público el nombramiento de Román Fernández-Baca como director del IAPH, anteriormente creado por el Decreto 107/1989, de 16 de mayo.

${ }^{14}$ Ese año de 1990 se crea el Centro Andaluz de Arte Contemporáneo, que residirá en el que fue Conjunto Monumental de la Cartuja a partir de 1998 retomando el uso museístico también previsto en el citado Plan Director de Usos.

${ }^{15}$ Hubo otra sede en Málaga, posteriormente, de vida fugaz.

${ }^{16}$ Se trataba de entrar en coherencia con la Declaración de Río sobre el Medio Ambiente y el Desarrollo de 1992.

${ }^{17}$ Declaración de México de 1982 de Políticas Culturales.

${ }^{18}$ Los debates y cursos generan cuadernos de alto contenido disciplinar, publicados desde 1994, como Patrimonio y ciudad: reflexión sobre centros históricos; Conservación arqueológica: reflexión y debate sobre teoría y práctica (Sevilla 1992); Arquitectura y Patrimonio: memoria del futuro. Una reflexión sobre la relación entre patrimonio y arquitectura, un curso-debate de 1992 también publicado en 1994, o Antropología y Patrimonio: Investigación, documentación e intervención, de 2003 dentro de la colaboración entre el IAPH y la editorial Comares, entre otros muchos.

${ }^{19}$ Los objetivos y funciones encomendados al centro desde su puesta en funcionamiento en 1997 se han desarrollado en el documento El Centro de Arqueología Subacuática, X Aniversario, de enero 2008. En línea: <http://www.iaph.es/ export/sites/default/galerias/arqueologiasubacuatica/documentos/xPDF-1x_El_ Centro_de_Arqueologxa_Subacuxtica.pdf> [Consulta: 04/09/2018]

20 Determinará el proceso para la definición del Registro Andaluz de Arquitectura Contemporánea.

${ }^{21}$ Durante la celebración de la Expo'92, la sede sevillana del joven IAPH ya acogió una exposición sobre el paisaje mediterráneo, cuya carta fue anticipadora del convenio europeo.

${ }^{22}$ Françoise Choay criticará más tarde la problemática de los lugares labelizados, al respecto de los reconocimientos derivados de la asunción por UNESCO de los valores universales excepcionales, al requerir necesarias estructuras de acogida, generar la eliminación de actividades creativas ligadas a la cultura local y su identidad, entendiendo que la edificación material de nuestro marco de vida produce la misma competencia simbólica que el lenguaje, que la competencia de hablar un lenguaje articulado entre locutor y auditor es la misma que compromete, con la competencia de edificar, a constructor y habitante (CHOAY, 2009).

${ }^{23}$ Especial Monográfico: Restauración democrática, en revista PH 50 (2004).

${ }^{24}$ Decreto 75/2008, de 4 de marzo, por el que el Instituto Andaluz del Patrimonio Histórico se adapta a la Ley 9/2007, de 22 de octubre, de la Administración de la Junta de Andalucía, y se aprueban sus Estatutos. Decreto 414/2008, de 15 de julio, por el que se modifican los Estatutos del Instituto Andaluz del Patrimonio Histórico, aprobados por el Decreto 75/2008, de 4 de marzo.

${ }^{25}$ La Ley 14/2007, de 26 de noviembre, del Patrimonio Histórico de Andalucía define la RECA como "un sistema integrado y unitario formado por aquellos Espacios Culturales ubicados en el territorio de la Comunidad Autónoma que sean incluidos en la misma por la Consejería competente en materia de patrimonio histórico, así como aquellos Enclaves abiertos al público, que por sus condiciones y características 
no requieran la dotación de un órgano de gestión propio". A diferencia de los museos y colecciones museográficas, los espacios culturales se definen no por los bienes que albergan sino por los inmuebles y conjuntos arquitectónicos que los componen. Actualmente forman parte de la Red ocho conjuntos culturales y 23 enclaves, en general arqueológicos. La Consejería ha definido asimismo un Registro de Museos de Andalucía y un Directorio de Enclaves.

${ }^{26}$ Textualmente, los conjuntos asumirán funciones generales de administración y custodia de los bienes que tengan encomendados y, especialmente, formularán y ejecutarán un plan director que desarrollará programas en materia de investigación, protección, conservación, difusión y gestión de los bienes tutelados y, en general, cuantas les sean encomendadas por la Consejería competente en materia de patrimonio histórico.

${ }^{27}$ Disponible en <http://www. alhambra-patronato.es/index.php/PlanDirector-2007-2020/803/0/> [Consulta: 04/09/2018].

${ }^{28}$ Plan Director del Conjunto Arqueológico de Itálica. Documento de Avance (junio 2011). Disponible en <http://www. juntadeandalucia.es/cultura/publico/BBCC/ PDI.Completo.pdf> [Consulta: 04/09/2018]
${ }^{29}$ Documento de Avance (anexado al texto de la candidatura a la Lista de Patrimonio Mundial). Doisponible en <https://whc. unesco.org/en/list/1560/documents/> [Consulta: 04/09/2018]

${ }^{30}$ Comprendía: a) III Plan General de Bienes Culturales. b) Plan General de las Instituciones Culturales. c) Plan General de Creación Artística y Literaria. d) Plan General de Recursos Culturales.

${ }^{31} \mathrm{Al}$ texto de este Plan se tiene acceso en <http://www.juntadeandalucia.es/export/ drupaljda/III\%2OPGBC.pdf> [Consulta: 04/09/2018].

${ }^{32}$ Téngase en cuenta que la Junta de Andalucía gestiona 25 instituciones museísticas en las 8 provincias (17 museos, 6 conjuntos arqueológicos y 2 conjuntos monumentales), a lo que se suman diecinueve enclaves de carácter arqueológico y cuatro monumentales.

${ }^{33}$ Instituto Andaluz del Patrimonio Histórico. Recomendaciones técnicas para la participación social en la gestión de los paisajes culturales. 2011. Disponible en <http:// hdl.handle.net/11532/161556> [Consulta: 04/09/2018]. Asimismo, Instituto Andaluz del Patrimonio Histórico. Recomendaciones técnicas para la documentación de paisajes de interés cultural. 2015. Disponible en <http://hdl.handle.net/11532/163070> [Consulta: 04/09/2018].
${ }^{34}$ Avance del Plan Estratégico 20122015. Disponible en <http://www juntadeandalucia.es/export/drupaljda/ PLAN\%2OESTRATEGICO\%2OIAPH\%2O2O122015.pdf> [Consulta: 04/09/2018]

${ }^{35}$ IAPH: Plan anual 2017. Previsión de actuaciones. Con acceso en <https://www. iaph.es/export/sites/default/galerias/elinstituto/descargas/iaph_plan_anual_2017. pdf> [Consulta: 04/09/2018].

${ }^{36}$ IAPH Memoria anual 2016. Con acceso en <https://www.iaph.es/export/sites/ default/galerias/el-instituto/descargas/ iaph_memoria_anual_2016.pdf> [Consulta: 04/09/2018].

${ }^{37}$ Centro de Documentación y Estudios del IAPH. Breve trayectoria, proyectos, servicios y productos de información, de octubre de 2016. Con acceso en <https://repositorio. iaph.es/bitstream/11532/310406/1/ DOSSIER_CENTRO_DOC_Y_ESTUDIOS IAPH_2016_10.pdf> [Consulta: 04/09/2018] y también Valoración e impacto de la gestión de la información del patrimonio cultural del IAPH, de septiembre de 2016 Con acceso en <https://repositorio.iaph. es/bitstream/11532/310353/2/Valoracion_ Impacto_Definitivo_2017.pdf> [Consulta: 04/09/2018].

${ }^{38}$ 2018, Año Europeo del Patrimonio Cultural. 


\section{Bibliografía}

ACOSTA BONO, G.; FERNÁNDEZ CACHO, S.; FERNÁNDEZ-BACA CASARES, R. (2017) El patrimonio cultural en la Estrategia de Paisaje de Andalucía. e-rph: Revista electrónica de Patrimonio Histórico [en línea], n. ${ }^{\circ}$ 20, 2017, pp. 104-131. <http:// revistaseug.ugr.es/index.php/erph/article/ view/6294> [Consulta: 09/08/2018]

ACTAS de la III Bienal de Restauración Monumental Sobre la des-Restauración, 2006 (2008) [en línea] Sevilla: Consejería de Cultura, Instituto Andaluz del Patrimonio Histórico; Academia del Partal, 2008 <http://www.academiadelpartal.org/files/ actas_3_bienal_restauracion_monumental. pdf> [Consulta: 20/07/2018]

ALIBRANDI, T.; FERRI, P. (1988) // diritto dei beni culturali. La protezione del patrimonio storico-artistico. Roma: Nuova Italia Scientifica, 1988

ALIBRANDI, T.; FERRI, P. (1978) I beni culturali e ambientali. Milán: Giuffrè, 1978

ANDRIEUX, J.-Y. (ed.) (2011) Patrimoine. Sources et paradoxes de l'identité. Rennes: Presses Universitaires de Rennes, 2011

BARRERO RODRÍGUEZ, M. C. (2012) La ciudad histórica ante un nuevo modelo urbanístico. Patrimonio cultural y derecho, n. ${ }^{\circ} 16,2012$, pp. 137-161

BARRERO RODRÍGUEZ, M. C. (2007) Las innovaciones de la Ley 14/2007, de 26 de noviembre, del Patrimonio Histórico de Andalucía en la ordenación urbanística de los conjuntos históricos. Revista Andaluza de Administración Pública, n. 68, 2007, pp. 73-111

BARRERO RODRÍGUEZ, M. C. (1990) La ordenación jurídica del patrimonio histórico. Madrid: Civitas, 1990

BECERRA GARCÍA, J. M. (2017) La conservación de la ciudad patrimonial. El planeamiento urbanístico como instrumento para la protección [en línea] Tesis doctoral. Universidad de Sevilla, 2017. <http://hdl.handle.net/11441/64981> [Consulta: 20/07/2018]

BECERRA GARCÍA, J. M. (2010) El patrimonio histórico y el planeamiento urbanístico en Andalucía. En BECERRA GARCÍA, J. M. (coord.) El Nuevo Marco Legal del Patrimonio Histórico Andaluz. Sevilla: Instituto Andaluz de la Administración Pública, 2010, pp. 31-54

BECERRA GARCÍA, J. M. (2000) EI planeamiento como instrumento para la protección de los conjuntos históricos. $\mathrm{PH}$ : Boletín del Instituto Andaluz del Patrimonio Histórico [en línea], n. ${ }^{\circ}$ 30, 2000, pp. 113 116. <http://www.iaph.es/revistaph/index. php/revistaph/article/view/955> [Consulta: o9/08/2018]

BELLINI, A. et al. (1990) Restauro architettonico: il tema dell'uso. Rávena: Essegi, 1990

BRIFFAUD, S. (2003) Le paysage comme patrimoine. En RICHET, J.-M. (ed.) Actes des Entretiens du Patrimoine. Le Regard de l'Histoire. L'Émergence et l'évolution de la notion de patrimoine au cours du XXe siècle en France. París: Arthème Fayard; Centre des monuments nationaux, Éditions du Patrimoine, 2003, pp. 243-251

CARAVACA BARROSO, I.; COLORADO CAMPOS, D.; FERNÁNDEZ SALINAS, V.; PANEQUE SALGADO, P.; PUENTE ASUERO, R.; ROMERO MORAGAS, C. (1997) Patrimonio cultural, territorio y políticas públicas. El caso de Andalucía. Estudios Regionales [en línea], n. ${ }^{\circ} 47$, 1997, pp. 143160. <http://www.revistaestudiosregionales. com/documentos/articulos/pdf520.pdf> [Consulta: 08/08/2018]

CARBONARA, G. (ed.) (1996) Trattato di restauro architettonico. Turín: UTET, 1996, 4 vols.

CARBONARA, G. (1990) Restauro dei monumenti. Guida agli elaborati grafici. Napoli: Liguori, 1990

CASTILLO RUIZ, J. (coord.) (2013) Carta de Baeza sobre patrimonio agrario. Baeza: Universidad Internacional de Andalucía, 2013

CASTILLO RUIZ, J. (2009) La dimensión territorial del patrimonio histórico. En CASTILLO RUIZ, J.; CEJUDO GARCÍA E.; ORTEGA, A. (coord.) Patrimonio histórico y desarrollo territorial. Sevilla: UNIA, 2009, pp. 27-48

CASTILLO RUIZ, J. (2003) Patrimonio y desarrollo local: sí, pero... PH: Boletín del Instituto Andaluz del Patrimonio Histórico [en línea], n. ${ }^{\circ}$ 42, 2003, pp. 89-90. <http:// www.iaph.es/revistaph/index.php/ revistaph/article/view/1470> [Consulta: 08/08/2018]

CASTILLO RUIZ, J. (1996) ¿Hacia una nueva definición del Patrimonio Histórico? Reflexiones sobre el documento "Bases para una Carta sobre Patrimonio y Desarrollo en Andalucía". PH: Boletín del Instituto Andaluz del Patrimonio Histórico [en línea], n. ${ }^{16}$, 1996, pp. 101-106. <http:// www.iaph.es/revistaph/index.php/ revistaph/article/view/381> [Consulta: 08/08/2018]

CHOAY, F. (2009) Le patrimoine en questions: anthologie pour un combat. París: Seuil, 2009
CHOAY, F. (1992) L'allégorie du patrimoine. París: Seuil, 1992

CLEMENTI, A.; PEREGO, F. (ed.) (1988) Memorabilia. Il futuro della memoria. Beni ambientali, architettonici, artistici e storici in Italia. Confronti per l'innovazione. Roma; Bari: Laterza, 1988

CONSEJERÍA DE CULTURA (1989)

Andalucía, diez años de Cultura. 1978-1988. Sevilla: Consejería de Cultura, 1989

CONTI, A. (1988) Storia del restauro e della conservazione delle opere d'arte. Milán: Electa, 1988

DEZZI BARDESCHI, M. (2004) Autenticità materiale contro mera analogía formale: due nozioni (e due diverse scelte) in ogni parte del mondo. En VALTIERI, S. (ed.) Della Bellezza ne è piena la vista! Restauro e conservazione alle latitudini del mondo nell'era della globalizzazione. Roma: Nuova Argos, 2004, pp. 133-148

FEIFFER, C. (1989) /l progetto di conservazione. Milán: Franco Angeli, 1989

FERNÁNDEZ-BACA CASARES, R. (2017) 50 años de Bienes Culturales desde la experiencia del IAPH. Tesis doctoral inédita. Universidad de Sevilla, 2017

FERNÁNDEZ-BACA CASARES, R. (2001) Diez años desde el Instituto Andaluz del Patrimonio Histórico. PH: Boletín del Instituto Andaluz del Patrimonio Histórico (Especial monográfico: Institutos de patrimonio) [en línea], n. ${ }^{\circ}$ 37, 2001, pp. 148 155. <http://www.iaph.es/revistaph/index. php/revistaph/article/view/1282> [Consulta: 09/08/2018]

FERNÁNDEZ-BACA CASARES, R.; CASTELLANO BRAVO, B.; FERNÁNDEZ CACHO, S.; GARCÍA DE CASASOLA GÓMEZ, M.; REY PÉREZ, J.; VILLALOBOS GÓMEZ, A. (2007) Acciones en el paisaje cultural de la Ensenada de Bolonia, Cádiz. PH: Boletín del Instituto Andaluz del Patrimonio Histórico [en línea], n. ${ }^{\circ} 63,2007$, pp. 92-113. <http:// www.iaph.es/revistaph/index.php/revistaph/ article/view/2403> [Consulta: 09/08/2018]

FERNÁNDEZ-BACA CASARES, R.; FERNÁNDEZ CACHO, S.; SALMERÓN ESCOBAR, S. (dir.) (2017) Guía del Paisaje Histórico Urbano de Sevilla. Sevilla: Instituto Andaluz del Patrimonio Histórico, 2017

FERNÁNDEZ-BACA CASARES, R.; GARCÍA DE CASASOLA GÓMEZ, M.; CASTELLANO BRAVO, B. (2014) Intervenir en el paisaje cultural construyendo soportes para mejorar la lectura patrimonial de la Ensenada de Bolonia. Informes y trabajos, n. 10,2014 , pp. 7-36 
FERNÁNDEZ-BACA CASARES, R.; LLEÓ CAÑAL, V.; MOSQUERA ADELL, E.; PÉREZ DEL CAMPO, L.; RODRÍGUEZ RUIZ, D.; SAMBRICIO RIVERA-ECHEGARAY, C. (2004) Informe sobre los valores patrimoniales del Palacio de San Telmo de Sevilla. PH: Boletín del Instituto Andaluz del Patrimonio Histórico [en línea], n. 51,2004 , pp. 36-41. <http:// www.iaph.es/revistaph/index.php/revistaph/ article/view/1864> [Consulta: 09/08/2018]

FERNÁNDEZ-BACA CASARES, R.; SALMERÓN ESCOBAR, P.; SANZ, N. (coord.) (2011) El paisaje histórico urbano en las ciudades históricas patrimonio mundial: indicadores para su conservación y gestión II. Sevilla: Instituto Andaluz del Patrimonio Histórico, 2011

FERNÁNDEZ-BACA CASARES, R:; SALMERÓN ESCOBAR, P.; SANZ, N. (coord.) (2009) El paisaje histórico urbano en las ciudades históricas patrimonio mundial: indicadores para su conservación y gestión. Sevilla: Instituto Andaluz del Patrimonio Histórico, 2009

FERNÁNDEZ CACHO, S. (2014) Estrategias para la gestión sostenible de los paisajes de interés cultural en Andalucía. En MARTíNEZ QUINTANA, J.; DEL POZO LÓPEZ, M. (coord.) Las Médulas. Paisajes Culturales: gestión del territorio. s.l.: Ayuntamiento de Aranjuez; Junta de Castilla y León y otros, 2014, pp. 3-24

FERNÁNDEZ CACHO, S. (2008) Patrimonio arqueológico y planificación territorial: estrategias de gestión para Andalucía. Sevilla: Consejería de Cultura, 2008

FERNÁNDEZ CACHO, S.; ARENILLAS TORREJÓN, J. A.; MONDÉJAR FERNÁNDEZ DE QUINCOCES, P.; ORTIZ LOZANO, L.; SORO CAÑAS, S. (2017) Evaluación de la gestión y uso de la información de la Guía Digital del Patrimonio Cultural de Andalucía. PH: Boletín del Instituto Andaluz del Patrimonio Histórico [en línea], n. 9 92, 2017. pp. 146-168. <http://www.iaph.es/revistaph/ index.php/revistaph/article/view/3974> [Consulta: 09/08/2018]

FERNÁNDEZ CACHO, S.; FERNÁNDEZ SALINAS, V.; HERNÁNDEZ LEÓN, E. (2010) Paisaje y Patrimonio Cultural en Andalucía. Tiempo, Usos e Imágenes. Sevilla: Instituto Andaluz del Patrimonio Histórico, 2010, 2 vols.

FERNÁNDEZ CACHO, S.; FERNÁNDEZ SALINAS, V.; RODRIGO CÁMARA, J. M.; DÍAZ IGLESIAS, J. M.; DURÁN SALADO, I.; SANTANA FALCÓN, I.; CUEVAS GARCÍA, J.; GONZÁLEZ SANCHO, B.; LÓPEZ MARTÍN, E. (2015) Balance y perspectivas del Registro de Paisajes de Interés Cultural de Andalucía. PH: Boletín del Instituto Andaluz del Patrimonio Histórico [en línea], n. ${ }^{88}$, 2015, pp. 166-189. <http://www.iaph.es/ revistaph/index.php/revistaph/article/ view/3667/3710> [Consulta: 09/08/2018]
FERNÁNDEZ LACOMBA, J.; ROLDÁN CASTRO, F.; ZOIDO NARANJO, F. (coord.) (2003) Territorio y Patrimonio: Los Paisajes Andaluces. Sevilla: Instituto Andaluz del Patrimonio Histórico, 2003

FERNÁNDEZ SALINAS, V. (coord.) (1996) Bases para una Carta sobre Patrimonio y Desarrollo en Andalucía. Sevilla: Instituto Andaluz del Patrimonio Histórico, 1996

FERNÁNDEZ SALINAS, V.; CARAVACA BARROSO, I.; SÁNCHEZ DE LAS HERAS, C. (coord.) (2005) Patrimonio y Desarrollo Territorial. Actas de las Jornadas de Patrimonio y Territorio. Sevilla: Consejería de Cultura de la Junta de Andalucía, 2005

FRANCESCHINI, F. (prefacio) (1967) Per la salvezza dei Beni Culturali in Italia. Atti e documenti della Commissione d'indagine per la tutela e valorizazzione del patrimonio storico, archeologico, artistico e del paesaggio. Roma: Casa Editrice Colombo, 1967, 3 vols.

GARCÍA CANCLINI, N. (1990) Culturas hibridas. Estrategias para entrar y salir de la modernidad. México D. F.: Grijalbo, 1990

HENARES CUÉLLAR, I. (ed.) (2010) La protección del Patrimonio Histórico en la España democrática. Granada: Universidad de Granada, 2010

INVENTARIO de recursos de la Comarca de La Loma. Módulos de promoción y desarrollo de las escuelas taller de úbeda y Baeza (1994). Madrid: Fundación Cultural Banesto, 1994

JOKILEHTO, J. (2009) Conservation Principles in the International Context. En RICHMOND, A.; BRACKER, A. (ed.) Conservation. Principles, Dilemmas and Uncomfortable Truths. Oxford: ButterworthHeinemann, 2009, pp. 73-83

LÓPEZ RECHE, G. (2008) La Ley 14/2007, de 26 de noviembre, del Patrimonio Histórico de Andalucía. Primera aproximación. Sevilla: Consejería de Cultura, 2008

LÓPEZ RECHE, G. (2004) El Plan General de Bienes Culturales Andalucía 2000. Definición de la actuación político-cultural de la administración autonómica. PH: Boletín del Instituto Andaluz del Patrimonio Histórico [en línea], n. ${ }^{\circ}$ 48, 2004, pp. 110-111. <http://www.iaph.es/revistaph/index.php/ revistaph/article/view/1740> [Consulta: 08/08/2018]

LOWENTHAL, D. (1985) The Past is a Foreign Country. Cambridge: Cambridge University Press, 1985

MARCONI, P. (1993) II restauro e l'architetto: teoria e pratica in due secoli di dibattito. Venecia: Marsilio, 1993
MARTÍNEZ YÁÑEZ, C. (2008)

Patrimonialización del territorio y territorialización del patrimonio. Cuadernos de Arte de la Universidad de Granada, n. 39, 2008, pp. 251-266

MONTUFO MARTÍN, A. M. (2017) La Protección Patrimonial del Territorio. Teorías, Conceptos Normativos y Casos de Estudio en Granada. e-rph: Revista electrónica de Patrimonio Histórico [en línea], n. ${ }^{20}$, 2017, pp. 5-56. <http://www. revistadepatrimonio.es/revistas/numero20/ legislacion/estudios/articulo.php> [Consulta: 09/08/2018]

MORALES MIRANDA, J. (2001) Guía práctica para la interpretación del patrimonio. Sevilla: Consejería de Cultura; Tragsa, 2001

MORENTE DEL MONTE, M. (2006) Introducción. El concepto actual de Patrimonio Cultural. PH: Boletín del Instituto Andaluz del Patrimonio Histórico (Especial Monográfico: Concepto de patrimonio cultural) [en línea], n. ${ }^{\circ}$ 58, 2006, pp. 40-43. <http://www.iaph.es/revistaph/index.php/ revistaph/article/view/2173> [Consulta: 09/08/2018]

MUÑOZ CRUZ, V. (2014) Los recursos culturales del Andévalo Occidental. Hacia nuevas formas de gestión patrimonial desde el territorio. Trabajo Fin de Máster inédito. Universidad de Sevilla, Máster en Arquitectura y Patrimonio Histórico, 2014

ORTIZ SÁNCHEZ, M. (2011) Las zonas patrimoniales: Una nueva tipología de protección en la Ley 14/2007, de 26 de noviembre, de Patrimonio Histórico de Andalucía. Revista Andaluza de Administración Pública, n. ${ }^{\circ}$ 79, pp. 91-133

ORTIZ SÁNCHEZ, M. (2010) Las zonas patrimoniales en el Ordenamiento Jurídico de Andalucía. Trabajo Fin de Máster inédito. Universidad de Sevilla, Máster en Arquitectura y Patrimonio Histórico, 2010

PEREGO, F. (ed.) (1987) Anastilosi. L'antico, il restauro, la città. Bari: Laterza, 1987

PÉREZ CANO, M. T. (2001) Turismo en las ciudades históricas: la ciudad sostenible. PH: Boletín del Instituto Andaluz del Patrimonio Histórico [en línea], n. 36, 2001, pp. 110-115. <http://www.iaph.es/revistaph/ index.php/revistaph/article/view/1227> [Consulta: 09/08/2018]

PÉREZ CANO, M. V.; PÉREZ DEL CAMPO L.; VILLANUEVA ROMERO, E.; FERRERAS ROMERO, G.; CASTELLANO BRAVO, B. (2011) Generar proyectos, sumar ideas: el retablo de Santa Ana en Triana (Sevilla). PH: Boletín del Instituto Andaluz del Patrimonio Histórico [en línea], n. ${ }^{\circ}$ 78, 2011, pp. 78-97. $<$ http://www.iaph.es/revistaph/index.php/ revistaph/article/view/3153> [Consulta: 09/08/2018] 
PÉREZ DEL CAMPO, L. (1999) Hacia una Convención Internacional para la protección del Patrimonio Histórico Subacuático. PH: Boletín del Instituto Andaluz del Patrimonio Histórico [en línea] n. 26 , 1999, pp. 99-109. <http://www.iaph. es/revistaph/index.php/revistaph/article/ view/770> [Consulta: 08/08/2018]

PÉREZ DEL CAMPO, L. (coord.) (1996) El Centro de Intervención en el Patrimonio Histórico: método, objetivo y servicios. PH: Boletín del Instituto Andaluz del Patrimonio Histórico [en línea], n. 14, 1996, pp. 47-56. <http://www.iaph.es/revistaph/index.php/ revistaph/article/view/296> [Consulta: 08/08/2018]

PÉREZ YRUELA, M.; VIVES, P. A. (2012) La política cultural en Andalucía. RIPS, vol. 11 (3) 2012 , pp. $65-87$

PLATA GARCÍA, F.; RIOJA LÓPEZ, C. (2002) La Antropología en la tutela del patrimonio. PH: Boletín del Patrimonio Histórico [en línea], n. ${ }^{\circ} 38,2002$, pp. 47-48. <http://www. iaph.es/revistaph/index.php/revistaph/ article/view/1318> [Consulta: 08/08/2018]

PLATA GARCÍA, F. (2017) La catalogación de bienes patrimoniales como servicio público y la participación social como necesidad: nuevos y viejos objetivos, retos y cauces tras treinta años de competencias de la Junta de Andalucía [en línea]. Tesis doctoral. Universidad de Sevilla, 2017. <https://hdl.handle.net/11441/70661> [Consulta:26/07/2018]

POULOT, D. (1997) Introduction générale En GRANGE, D. J.; POULOT, D. (ed.) L'esprit des lieux. Le patrimoine et la cité. Grenoble: Presses Universitaires de Grenoble, 1997, p. 30

QUEROL, M. A. (2010) Manual de gestión del Patrimonio Cultural. Madrid: Akal, 2010

RIVERA BLANCO, J. (2001) Instrumentos para la política cultural y el desarrollo sostenible: el IAPH y otros centros de patrimonio en España. PH: Boletín del Instituto Andaluz del Patrimonio Histórico [en línea], n. 37, 2001, pp. 169-177 (Especial monográfico: Institutos de Patrimonio). <http://www.iaph.es/revistaph/index.php/ revistaph/article/view/1285> [Consulta: 08/08/2018]

RODRÍGUEZ DE GUZMÁN SÁNCHEZ, S. (2005) El planeamiento como modo de protección del Patrimonio Arqueológico: el caso de la Comunidad Autónoma de Andalucía. En Actas de las Primeras Jornadas de Patrimonio Arqueológico en la Comunidad de Madrid [en línea]. Madrid: Consejería de Cultura y Deportes. Dirección General de Patrimonio Histórico, 2005, pp. 15-38. <http://www.madrid.org/cs/BlobServ er?blobkey=id\&blobwhere=1220574614722\& blobheader=application\%2Fpdf\&blobheade
rname1=Content-Disposition\&blobheader alue1=filename\%3D1+-+Arqueolog\%C3\%AD $a+d e+l o s+y a c i m i e n t o s+e x t e n s o s+y+u r b a n i s$ mo.pdf\&blobcol=urldata\&blobtable=Mungo Blobs> [Consulta: 20/07/2018]

RODRÍGUEZ TEMIÑO, I. (1998) La tutela de Patrimonio Histórico de la modernidad a la posmodernidad. PH: Boletín del Instituto Andaluz del Patrimonio Histórico [en línea] n. ${ }^{\circ}$ 23, 1998, pp. 84-96. <http://www.iaph es/revistaph/index.php/revistaph/article/ view/650> [Consulta: 08/08/2018]

ROMERO MORAGAS, C. (2008) Veinticinco años de políticas de patrimonio cultural en Andalucía. Políticas regionales y locales de tutela y valorización del patrimonio cultural. Actualidad, interacciones y perspectivas. Ciudad Rodrigo: Fundación de las Universidades de Castilla y León, 2008

ROMERO MORAGAS, C. (1993) Patrimonio y desarrollo. PH: Boletín del Instituto Andaluz del Patrimonio Histórico [en línea], n. 4 , 1993, pp. 1-2. <http://www.iaph.es/revistaph/ index.php/revistaph/article/view/30> [Consulta: 08/08/2018]

RUIZ GONZÁLEZ, B. (1995) El Plan General de Bienes Culturales de Andalucía para el periodo 1996-1999. PH: Boletín del Instituto Andaluz del Patrimonio Histórico [en línea], n. ${ }^{\circ} 12,1995$, p. 11. <http://www.iaph. es/revistaph/index.php/revistaph/article/ view/221> [Consulta: 08/08/2018]

SALVATIERRA CUENCA, V. (1994a) Historia y desarrollo del modelo andaluz de Arqueología. Trabajos de Prehistoria [en línea], vol. 51(1), 1994, pp. 1-13. <http:// tp.revistas.csic.es/index.php/tp/article/ view/461> [Consulta: 08/08/2018]

SALVATIERRA CUENCA, V. (1994b) Arqueología urbana: investigación y gestión. La situación en Andalucia. Arqueología y Territorio Medieval [en línea] vol. 1, 1994, pp. 75-82 . <http://www.ujaen. es/revista/arqytm/PDF/R1/R1_6_Salvatierra. pdf> [Consulta: 25/07/2018]

SALMERÓN ESCOBAR, P. (coord.) (2004) Bolonia Guía del Paisaje Cultural de la Ensenada de Bolonia. Avance. Sevilla: Instituto Andaluz del Patrimonio Histórico, 2004

SAN MARTÍN MONTILLA, C. (1998) E museo integral del territorio. Una propuesta para los museos locales y comarcales de Andalucía. RdM. Revista de Museología: Publicación científica al servicio de la comunidad museológica, n. ${ }^{13}$, 1998, pp. 43-52

SAN MARTÍN MONTILLA, C. (1994a) La protección del Patrimonio Arqueológico desde el museo: Criterios de difusión. PH: Boletín del Instituto Andaluz del Patrimonio Histórico [en línea], n. 7, 1994, pp. 26-28. <http://www.iaph.es/revistaph/index.php/ revistaph/article/view/110> [Consulta: 25/07/2018]

SAN MARTÍN MONTILLA, C. (1994b) La protección del Patrimonio Arqueológico desde el museo (II): Criterios de difusión. PH: Boletín del Instituto Andaluz del Patrimonio Histórico [en línea], n. ${ }^{\circ}$, 1994, pp. 14-16. <http://www.iaph.es/revistaph/ index.php/revistaph/article/view/132> [Consulta: 25/07/2018]

SOUTIF, D. (2007) II patrimonio moderno e contemporaneo tra Francia e Italia. Stato, musei e collezioni. En CATONI M. L. (ed.) $1 /$ patrimonio culturale in Francia. Milán: Mondadori Electa, 2007, pp. 235-253

TORRES RIDRUEJO, A. (2012) La pretensión cautelar de suspensión de la obra de reforma del palacio de San Telmo y la importancia de los informes periciales. PH: Boletín del Instituto Andaluz del Patrimonio Histórico [en línea], n. 82 , 2012, pp. 2429 (Especial monográfico: Patrimonio y tribunales de justicia). <http://www.iaph. es/revistaph/index.php/revistaph/article/ view/3301> [Consulta: 09/08/2018]

VERDUGO SANTOS, J. (2010) Zonas

Patrimoniales y Espacios Culturales: Nuevas herramientas para la tutela del patrimonio en relación con el territorio. En BECERRA GARCÍA, J. M. (coord.) El Nuevo Marco Legal del Patrimonio Histórico Andaluz. Sevilla: Instituto Andaluz de la Administración Pública, 2010, pp. 55-73

VERDUGO SANTOS, J. (2005) El territorio como fundamento de una nueva retórica de los bienes culturales. PH: Boletín del Instituto Andaluz del Patrimonio Histórico [en línea], n. ${ }^{\circ}$ 53, 2005, pp. 94-105. <http://www.iaph.es/revistaph/index.php/ revistaph/article/view/1974> [Consulta: 09/08/2018]

WEIS, H. (ed.) (1989) La Muséologie selon Georges Henri Rivière: cours de muséologie, textes et témoignages. París: Dunod, 1989 